\title{
Promising cannabinoid-based therapies for Parkinson's disease: motor symptoms to neuroprotection
}

\author{
Sandeep Vasant More and Dong-Kug Choi
}

\begin{abstract}
Parkinson's disease (PD) is a slow insidious neurological disorder characterized by a loss of dopaminergic neurons in the midbrain. Although several recent preclinical advances have proposed to treat PD, there is hardly any clinically proved new therapeutic for its cure. Increasing evidence suggests a prominent modulatory function of the cannabinoid signaling system in the basal ganglia. Hence, use of cannabinoids as a new therapeutic target has been recommended as a promising therapy for PD. The elements of the endocannabinoid system are highly expressed in the neural circuit of basal ganglia wherein they bidirectionally interact with dopaminergic, glutamatergic, and GABAergic signaling systems. As the cannabinoid signaling system undergoes a biphasic pattern of change during progression of PD, it explains the motor inhibition typically observed in patients with PD. Cannabinoid agonists such as WIN-55,212-2 have been demonstrated experimentally as neuroprotective agents in PD, with respect to their ability to suppress excitotoxicity, glial activation, and oxidative injury that causes degeneration of dopaminergic neurons. Additional benefits provided by cannabinoid related compounds including CE-178253, oleoylethanolamide, nabilone and HU-210 have been reported to possess efficacy against bradykinesia and levodopa-induced dyskinesia in PD. Despite promising preclinical studies for PD, use of cannabinoids has not been studied extensively at the clinical level. In this review, we reassess the existing evidence suggesting involvement of the endocannabinoid system in the cause, symptomatology, and treatment of PD. We will try to identify future threads of research that will help in the understanding of the potential therapeutic benefits of the cannabinoid system for treating PD.
\end{abstract}

Keywords: Basal ganglia, Cannabinoids, CB1 receptors, CB2 receptors, Endocannabinoid signaling system, Neuroprotection, Parkinson's disease

\section{Introduction}

Parkinson's disease and cannabinoid system: prevalence and disease pathology

Parkinson's disease (PD) is the second most common neurodegenerative disorder mainly affecting $1 \%$ of the elderly population [1]. In fact, age is the most critical risk factor for PD, and $1-2 \%$ of the world population $>65$ yr suffers from this slowly progressive degenerative disease [2]. The preponderance of patients with $\mathrm{PD}$ have an idiopathic disease (90-95\%) with no specific known cause, and the remaining have familial-inherited disease $(5-10 \%)$ [3]. The exclusive hallmark feature of PD is the accumulation of $\alpha$-synuclein protein, loss of dopaminergic neurons in

\footnotetext{
* Correspondence: choidk@kku.ac.kr

Department of Biotechnology, College of Biomedical and Health Science, Konkuk University, Chungju 380-701, South Korea
}

the substantia nigra pars compacta $(\mathrm{SNpc})$, which leads to depletion of dopamine in the striatum [4]. Several critical advances have been made in understanding the pathways that lead to cell dysfunction and death in PD. A few of these pathways include neuroinflammation, mitochondrial dysfunction, oxidative stress, kinase pathways, calcium dysregulation, protein aggregation, and prion-like processes. These pathways have helped to identify molecular targets [5], and based on experimental data, there has been a moderate increase in the tentative treatment choices for both early and later stages of PD and non-motor symptoms [6]. Although levodopa remains the primary mode of symptomatic treatment for PD, its chronic use is coupled with the development of motor complications such as response oscillations and levodopa-induced dyskinesia (LID), which affects 
$30-35 \%$ of patients after just 24 months of levodopa exposure. Thus, to avoid the motor complications arising with use of levodopa, on-going research pursues to develop new non-dopaminergic symptomatic agents capable to attenuate motor deficits and to restore dopamine transmission without producing dyskinesia [7]. Cannabinoids are one such interesting class of agents that not only have demonstrated neuroprotective ability but have also been evaluated for their potential to alleviate motor symptoms observed in PD. In this review we discuss the possibility of various cannabinoids and their respective target pathways that may hold potential to be used as an therapeutic for PD. Cannabinoids have been demonstrated to be effective in preclinical studies involving excitotoxicity, oxidative stress, neuroinflammation, and motor complications associated with PD [8].

The endocannabinoid (endogenous cannabinoid) system Considerable advances in our understanding of the elements of the ECB system have been made in the past 15 yr. Two major cannabinoid receptors, CB1 and CB2, have been cloned and several endogenous cannabinoids were identified along with their synthetic and degradative pathways. ECBs were discovered initially in the brain, but were also found in the periphery in humans and animals. ECBs are not only produced by cultured neurons [9], but also by microglia and astrocytes [10]. Years of research has identified few major ECBs such as arachidonoyl ethanolamide (anandamide, AEA), 2arachidonoyl glycerol (2-AG), O-arachidonoyl ethanolamine (virodhamine), and 2-arachidonoyl glyceryl ether (noladin ether) [11]. As bulk of the investigations relating to ECBs and $\mathrm{PD}$ has considered data relating to AEA and 2-AG, we would majoritively consider these two ECBs in our further discussion. AEA is mainly been localized in the brain and periphery [12]. AEA, besides having activity on CB1 and CB2 receptors, also has full agonistic activity at TRPV1 receptor [13]. AEA is well distributed in the brain and shows high distribution in the hippocampus, thalamus, striatum, and brainstem and to a lesser extent in the cerebral cortex and cerebellum [14]. Lower concentrations of AEA are found in human serum, plasma, and cerebrospinal fluid [15]. Similarly, 2-AG is observed in both the brain and periphery, although its concentration is almost 150 times higher in brain compared to that of AEA [16,14]. Higher 2-AG levels are found in rat hippocampus, brainstem, striatum, and medulla [16]. 2-AG has greater potency, stability and agonistic activity at $\mathrm{CB} 1$ and $\mathrm{CB} 2$ receptors compared to that of AEA [17-19]. Two prominent areas involved in the control of movement, such as the globus pallidus and the substantia nigra, not only contain the highest densities of CB1 receptors [20] but also the highest levels of ECBs, specifically anandamide [21].
The physical composition of the nerve cells that yield ECBs in the basal ganglia is currently unknown, although the basal ganglia contain the precursor of anandamide and N-arachidonoyl phosphatidylethanolamine [22], which strengthens the theory of in situ synthesis for this ECB. Synthesis of anandamide seems to be related to dopamine. This hypothesis was backed by Giuffrida et al., who demonstrated that anandamide synthesis is regulated by dopaminergic D2 receptors in the striatum [23], suggesting that the ECB system acts as an inhibitory feedback mechanism countering the dopamine-induced facilitation of motor activity [23].

\section{Synthesis and metabolism of endocannabinoids}

Distinct synthesizing and metabolizing enzymes have been identified, which actively regulate the levels of endogenous cannabinoids under normal and diseased conditions, and hence may be considered promising therapeutic targets. Both AEA and 2-AG are synthesized by cleavage of plasma membrane phospholipids, and calcium acts as a biosensor to depolarize the membrane to induce synthesis in an activity-dependent fashion [24]. AEA is synthesized by sequential actions of two intracellular enzymes, such as $\mathrm{N}$-acyl phosphatidylethanolamine-specific phospholipase $\mathrm{D}$ (NAPE-PLD) that catalyzes the release of anandamide by a phospholipase $\mathrm{D}$ from its precursor $\mathrm{N}$-arachidonoyl phosphatidylethanolamine and $\mathrm{N}$-acyltransferase that catalyzes the transfer of arachidonic acid to a molecule of phosphatidylethanolamine to generate the precursor [24]. In addition to these enzymes other enzymes, such as protein tyrosine phosphatase, non-receptor type 22, and $\alpha / \beta$ hydrolase 4 , are also involved in AEA production [25]. 2-AG is synthesized via three major pathways. The first pathway involves sn-1-diacylglycerol lipase $\alpha$ and $\beta$-mediated pathways $[26,27]$. Second pathway works via action of phospholipase-A1 to convert phosphatidyl lipid to 2-arachidonoyl lyso phosphatidyl lipid and then to 2-AG by the action of lyso-phospholipase-C. The third pathway includes hydrolysis of lipid phosphate by an lipid phosphate phosphatase [27]. Degradation of ECBs occurs rapidly in vivo [28-30]. FAAH is the predominant ECB metabolizing enzyme located intracellularly on post-synaptic neuron membranes [31-33]. FAAH is primarily responsible for breakdown of AEA, although 2-AG also acts as a substrate [33-35]. Monoacylglycerol lipase (MAGL) is a pre-synaptically localized enzyme that primarily inactivates 2-AG through hydrolysis to arachidonic acid and glycerol [36,37]. Apart from FAAH, acyl glycerol kinase [38], serine hydrolase $\alpha$ - $\beta$-hydrolase domain $6 / 12$ (ABHD6/12), lipoxygenase [39] and cyclooxygenase 2 (COX-2) also have roles to metabolise ECBs [24]. Although, COX-2 can only be considered as an alternative metabolic pathway addressed to the synthesis of novel bioactive lipids rather than a central degrading pathway. 
All these new metabolising enzymes produce different molecules like, prostaglandin glycerol esters, lysophosphatidic acid and hydroperoxy derivatives of 2-AG. These by-products often have antagonizing role as compared to 2-AG. Therefore, impeding these metabolic enzymes may also act as a therapeutic target [27]. ECBs are lipophilic molecules and hence are capable of passing through the plasma membrane if their intracellular concentration is less than their extracellular concentration. However, crossing the plasma membrane as a mechanism for inactivation is too slow a process. Thus, the AEA membrane transporter (AMT) is a protein proposed to facilitate diffusion of 2-AG inside cells. Although AMT has not been isolated or cloned, its existence remains debated. However, reports have established cellular uptake of virodhamine [40] by AMT.

\section{Cannabinoids: role in neuroprotection and control of motor functions in PD}

Cannabinoids have been contemplated as clinically neuroprotective molecules, as they can reduce oxidative injury, excitotoxicity, and calcium influx [41]. They also decrease inflammation by modulating glial processes that are associated with neuronal survival. Cannabinoids may provide neuroprotection in PD by means of these processes. Two important neuroprotective mechanisms are elicited by cannabinoids in experimental models of PD. First, they decrease increased oxidative stress in PD, a mechanism that seems to be independent of any involvement of cannabinoid receptors. Second, they increase density of CB2 cannabinoid receptors, mainly in reactive microglia, which regulate micro-functions of glial cells and homeostasis of surrounding neurons [42]. The basal ganglia is a part of a complex neuronal network that coordinates activity from different cortical regions that directly or indirectly participate in the control of movement [43]. Structural elements of basal ganglia include the corpus striatum and other subcortical regions such as subthalamic nucleus (STN), the substantia nigra and the pedunculopontine tegmental nucleus [43]. Historic and new data have empowered the notion of a marked role for the endocannabinoid (ECB) signaling system in the control of movement. This discovery is backed by three important lines of evidence. First, there is a marked presence of CB1 and CB2 receptors with vanilloid TRPV1 receptors coupled with ECBs in the basal ganglia and cerebellum, which are the areas that control movement. Second, there is evidence for a powerful inhibitory action of plantderived, synthetic and endogenous cannabinoids on motor activity by fine tuning the activity of various classical neurotransmitters. Third, prominent changes take place in transmission of ECBs in the basal ganglia of humans and in animal models of PD. These lines of evidence strengthen the idea that cannabinoids act on key pathways of ECB transmission including receptors, transporters, fatty acid amide hydrolase (FAAH), which might be of therapeutic interest because of their potential to mitigate motor symptoms [44]. Considering the appropriateness of this preclinical evidence and the lack of efficient therapeutic strategies for $\mathrm{PD}$, we will reassess the components of the ECB system with respect to their involvement in neuroprotection and alleviating the motor dysfunction associated with PD. We will also provide support for the hypothesis that modulators of the ECB system may have therapeutic potential for treating PD.

\section{Neuroanatomical basis for location and interaction between basal ganglial units and cannabinoid receptors} The molecular identification of the CB1 and CB2 receptors, the ion channel TRPV1, with their respective endogenous ligand systems has opened a whole arena of pharmacological effects elicited by each one of these specific receptor targets. CB1 and CB2 receptors belong to the superfamily of $\mathrm{G}$ protein-coupled receptors, which are coupled to inhibitory $\mathrm{G}$ proteins $[30,45,46]$. As such, both receptors inhibit adenylyl cyclase and activate mitogen activated protein kinase (MAPK) [47]. Moreover, presynaptically located $\mathrm{CB} 1$ receptors inhibit $\mathrm{N}$ and P/Q-type calcium channels and activate inwardly rectifying potassium channels [48-50]. Additional signaling mechanisms encompass focal phosphatidylinositol-3kinase, adhesion kinase, sphingomyelinase, and nitric oxide synthase (NOS) [51-55]. The cDNA for CB1 receptor was first isolated from a rat cerebral cortex library using an oligonucleotide probe resulting from a member of G-protein-coupled receptors [45]. CB1 receptors are most highly expressed on axons and nerve terminals, but substantial functional evidence also confirms their expression on somata $[47,56]$. Autoradiography investigations have convincingly reported that the basal ganglia encompass the highest levels of both mRNA expression and binding sites for the CB1 receptor $[57,58]$. Including striatum [59], other three regions that receive striatal efferent outputs, such as the globus pallidus, entopeduncular nucleus, and substantia nigra pars reticulata (SNpr), contain high levels of $\mathrm{CB} 1$ receptor binding sites $[20,60,61]$. However, CB1 receptor mRNA transcripts are also present in the caudate-putamen, which is deficient of striatal outflow nuclei [62]. This observation agrees with the concept that $\mathrm{CB} 1$ receptors are presynaptically located in striatal projection neurons, a belief that has been backed by a series of anatomical experiments in which specific subpopulations of neurons in the basal ganglia were lesioned $[63,64]$. CB1 receptors are positioned in striatonigral (direct striatal efferent pathway) and striatopallidal (indirect striatal efferent pathway) projection neurons [59,65], which use gamma-aminobutyric acid (GABA) as a neurotransmitter. Glutamic acid decarboxylase, prodynorphin, 
substance $\mathrm{P}$, as well as D1 or D2 dopaminergic receptors are other markers co-expressed in these pathways $[59,66]$. In contrast, intrinsic striatal neurons, which contain acetylcholine or somatostatin, do not express CB1 receptors [66]. Axon terminals and post-synaptic dendrites in the prefrontal cortex that express CB1 receptor are documented to have sub-cellular presence of D2 receptors [67]. Realtime PCR assays and quantitative autoradiography binding study demonstrated higher levels of cannabinoid receptor binding in the lateral globus pallidus and weaker CB1 receptor gene expression in the prefrontal cortex [68]. mRNA and autoradiographical studies revealed that the CB1 receptor is predominantly expressed in the sensory motor sectors of the striatum, with minor to minimal expression in associative/limbic striatal regions [69]. CB1 are localized both pre and post-synaptically. CB1 receptors are localized in GABAergic terminals of interneurons or collaterals from medium spiny neurons (MSNs), and also in glutamatergic but not in dopaminergic terminals Post-synaptically, CB1 receptors are localized in the somatodendritic area of MSN [70]. More extensive but less vigorous pre and post-synaptic CB1 receptor occurrence by electrophysiological and electron microscopic studies was also displayed in many brain regions including those enriched in dopaminergic neurons [71]. Thus displaying that the CB1 receptor is a significant retrograde signaling molecule in excitatory as well as in inhibitory-type axon terminals. Immunohistochemical, immunoblot [72] and autoradiographical studies have suggested the presence of CB1 receptor in substantia nigra, striatum and globus pallidus [73]. CB1 receptor immunolabeling is also abundant in SNpr [74]. Immunolabeling study by Matyas et. al; demonstrated that glutamatergic and GABAergic axon terminals in ventral tegmental area [75] and substantia nigra express CB1 receptor that target tyrosine hydroxylase containing dopaminergic projection neurons [76].

Another location for $\mathrm{CB} 1$ receptors in the basal ganglia is the subthalamopallidal and/or subthalamonigral glutamatergic terminals, as shown by the presence of measurable amounts of CB1 receptor mRNA in the subthalamic nucleus, coupled with the absence of detectable levels of cannabinoid receptor binding in that structure $[62,77]$. These anatomical studies and data strengthen the assumption that $\mathrm{CB} 1$ receptors play an important role in mediating the motor effects of various cannabinoid receptor agonists [78-80]. CB1 receptor expression is only partially known in glial cells. Microglia, astrocytes, and oligodendrocytes have been reported to express CB1 receptors $[81,82]$. CB1 immunoreactivity has been reported in perisynaptic and perivascular astrocytes [83] of rat striatum [84]. However, these data have not been reproduced by other researchers $[85,86]$. In addition, another study reported CB1 expression in primary astrocyte cultures and in astrocytoma cell lines [87,88]. Although CB1 expression on glial cells is debated, it is at a considerably lower density than that observed on neurons [47]. Primary microglial cell cultures express $\mathrm{CB} 1$ receptors. However, CB1 receptor expression is affected due to culture-influenced morphological changes that occur in microglia [81]. Thus, it is unclear whether the presence of CB1 receptors on microglia is a consequence of their activation, as there are no in vivo data regarding $\mathrm{CB} 1$ receptor expression in microglia. Carrier and colleagues reported that a non-transformed rat microglia cell line expresses CB1 receptors [89]. The functional relevance of CB1 receptors in microglial function remains dubious, although their role may be linked to nitric oxide $(\mathrm{NO})$ production [54], which is a pivotal event in microglia-mediated neuroinflammation [90].

A second cannabinoid receptor was discovered in a human promyelocytic cDNA library within a few years following discovery of the CB1 receptor. Based on its homology to the CB1 receptor and similar ligand binding profile, this receptor was named the CB2 receptor [46]. There has been uncertainty with CB2 receptor expression on neurons. Some evidence described CB2 receptor expression in rat dorsal root ganglion (DRG) cultures $[91,92]$ and F-11 cells that exhibits several features of authentic DRG neurons [93]. Related reports also indirectly displayed CB2 receptors on primary sensory neurons [94]. Furthermore, the localization of CB2 receptors in granules and purkinje cerebellar neurons of mouse brain was demonstrated [95,96]. CB2 receptors are primarily expressed on immune cells. Prolific expression of CB2 receptors is found in B-lymphocytes, natural killer cells, monocytes, neutrophils, T8 lymphocytes, and T4 lymphocytes [97]. Several other researchers have demonstrated the presence of CB2 receptors in in vitro cultures [98]. Specifically, mouse [99], primary rat [100-102], human [103], BV-2 [104], and RTMGL1 [89] microglial cells have been established to express CB2 receptors. Notably, CB2 receptor expression is affected due to culture-influenced morphological changes that occur in microglia [89]. However, data obtained by Benitoa and Nunez et al., indicate that CB2 receptors may be present in the perivascular microglial cells in normal pathologic human brains (cerebellum) $[105,106]$. Recent evidences through anatomical localization, behavioural studies for central effects of CB2 receptor agonists and mRNA expression profile in neurons are pointing towards the neuronal expression of CB2 receptors [107] in GABAergic neurons of layer II and V of medial entorhinal area of rats [108] as well as in CA1 hippocampus and substantia nigra [109]. Lately a report demonstrated the expression of CB2 receptors intracellularly in layer II/III pyramidal cells of the rodent medial prefrontal cortex [110]. Within the basal ganglia, CB2 receptors are also 
found to be expressed in neurons from both segments of the globus pallidus of Macaca fascicularis [111] and SNpr region of neonatal rats [112]. Immunohistochemical evidence suggests that activated microglia are able to express the CB2 cannabinoid receptor during chronic degenerative processes [113]. Past reports have also shown CB2 expression in neural progenitor cells [114]. These results indicate that CB2 might be involved in the neuroinflammatory process that develops in some forms of neurodegeneration such as PD [42]. Thus, various studies have established that CB2 receptors are significantly induced in different parts of brain, including the basal ganglia, in response to different types of insults including injury or inflammation $[105,115]$. Therefore, CB2 may become a promising target for modulating neuroinflammatory responses, as the agonists for this receptor are devoid of psychoactive effects $[81,116]$. The gist of these data is that immunocytochemical experiments claiming CB2 expression are several, but are often inconsistent. Also, before accepting any claim of CB2 expression in a specific tissue, the inclusion of coexisting and cautious controls is obligatory. Although these settings have been followed for many immune cells and neurons, but still many other tissues are yet to be established [116].

Some reports have also stated the importance of vanilloid TRPV1 receptors in the basal ganglia and their ability to interact with ECBs [117-119]. TRPV1 receptors have been studied for their role as molecular integrators of nociceptive stimuli present abundantly on sensory neurons. Apart from sensory neurons, TRPV1 receptors are also found in the basal ganglia circuitry co-localized with tyrosine hydroxylase, indicating that they are located in dopaminergic neurons of the nigrostriatal pathway $[117,120]$. Various neurochemical and pharmacological studies have reported the involvement of these receptors in the control of motor function [121] as well as in the manifestation of motor effects by certain cannabinoid receptor agonists [122]. Despite several reports in which these classical cannabinoid receptors do not explain the observed pharmacology, many studies using mice with genetically deleted $\mathrm{CB}$ receptors have confirmed the existence of additional targets, which are collectively known as non-CB1/CB2 receptors. Despite aggressive research efforts, the molecular identity of these non-CB1/CB2 receptors remains unclear [123]. The orphan G-proteincoupled receptor 55 (GPR55) has been discovered as another possible cannabinoid receptor [124]. In comparison to $\mathrm{CB}$ receptors, GPR55 is coupled to $\mathrm{Gq}, \mathrm{G \alpha} 12$, and Ga13 proteins [125]. Regardless of high GPR55 expression in the striatum [126], contrasting pharmacological data may not consider GPR55 as a novel cannabinoid receptor $[125,127,128]$.

\section{Pre-clinical and clinical manifestations displaying involvement of cannabinoids in PD}

The outcomes of various investigations on the status of the ECB system in PD patients indicates a similar trend as that observed in animal models of PD. The cannabinoid signaling system in PD becomes over activated in the basal ganglia [129-133]. Impacts of cannabinoids on motor activity depend on the effect of the cannabinoid on the dopaminergic system. Systemic administration of endogenous [(AEA) \& tetrahydrocannabinol (THC)] and synthetic cannabinoids [WIN-55,212-2, CP 55,940] typically inhibit motor activity and produce catalepsy in rodents [122,134-138]. A recent study has revealed a reduction in the availability of $\mathrm{CB} 1$ receptors in the SN of PD patients as compared with healthy controls [133]. Mice deficient of CB1 receptors display less severe dyskinesias, when lesioned with 6-hydroxy dopamine (6-OHDA) and treated with levodopa, compared with normal animals [139] thus, providing an indication for the participation of CB1-related mechanisms in motor regulation [140]. Electrophysiological studies have revealed that cannabinoid agonists increase the firing rate of SNpc neurons [141-143]. Mice lacking the CB1 receptor display a reduction in tyrosine hydroxylaselabeled varicosities, the majority of which are dopaminergic, in the accumbens shell as well as a loss of dopamine-dependent reward function [144]. In vivo microdialysis investigations have shown improved dopamine release in the striatum after administration of endogenous or exogenous cannabinoid agonists $[145,146]$. Patients with PD have increased efficacy of CB1 receptor activation along with an escalated binding of the CB1 receptor [129]. In addition, the cerebrospinal fluid of untreated patients with PD has augmented levels of AEA [147]. The outcome of a study involving the pattern and rate of cannabis use in almost 400 patients with PD revealed that $25 \%$ of patients had consumed cannabis and 45.9\% proclaimed benefits [148]. Notably, one of the key symptoms of PD, bradykinesia, was most frequently ameliorated by cannabinoids, which is followed by muscle rigidity and tremor [148]. Moreover, use of cannabis mitigates dyskinesias in $14 \%$ of patients with PD [148]. In a short pilot study involving patients with $\mathrm{PD}$, nabilone, a cannabinoid receptor agonist significantly decreased LID [149]. However, a larger, double-blind, randomized, placebo-controlled crossover trial demonstrated that orally administered cannabis extract was ineffective for alleviating parkinsonism or dyskinesia in patients with PD [150]. With respect to the neuroanatomical distribution, functional and behavioral studies, it suggests that the ECB system can act as an indirect modulator of dopaminergic neurotransmission in the basal ganglia which involves CB1 receptor mediated inhibition of GABA transmission. Another double-blind, randomized, 
placebo controlled study investigated the probable effects of antagonizing CB1 receptors in patients with PD, wherein progress in motor function or a decrease in LID was observed [151]. In another experimental randomized, double-blind, placebo-controlled trail, the CB1 receptor antagonist SR 141716 was ineffective for improving parkinsonian motor disability [151]. These discouraging outcomes indicate the necessity for more research in this area. Various facets concealing the relative "inadequacy" of these examinations might be different and probably are associated with the complex neuroanatomical network of the basal ganglia. Therefore, based on the above observations, we propose that a few CB1 receptor-related effects could be favored as compensatory mechanisms, whereas others effects might embody a part of the pathogenetic process, an issue that is further complicated with chronic L-DOPA use.

\section{Basal ganglial circuitry in PD and signaling of endocannabinoids}

Heterogeneous loss of dopaminergic neurons in the $\mathrm{SNpc}$ and their projecting fibers in the striatum are the core pathological features of PD. The striatal nucleus is the main input area to the basal ganglia, as it gathers and holds glutamatergic cortical inputs from all operative sub-sections of the neocortex and a remarkable input straight from the thalamic nuclei. The striatal network, which consists of GABAergic projecting MSNs contributing to the sole striatal output, and cholinergic interneurons carry out the neuronal signal processing functions from the cortex [59]. Two sets of neuronal circuits exist for striatal MSNs that connect to the output nuclei of the basal ganglia. One is a direct circuit (direct pathway) or via a sequence of connections that include the STN and the external segment of the globus pallidus (GPe) (indirect pathway) [152]. The output nuclei [SNpr and the internal segment of the globus pallidus (GPi)] connect to the thalamus, which further has efferent extensions that form the cortico-basal ganglia-thalamocortical loop [152]. The physiological effect of dopamine originating from the SNpc on MSNs is intricate and not fully revealed. In fact, the intensity of membrane depolarization on the dopamine receptor dictates the type of effect produced. D1 dopamine receptors are positively coupled to adenylyl cyclase; hence, their activation increases the cytosolic cAMP level and subsequently elicits numerous downstream effects including an increase in NMDA receptor-mediated currents. In contrast, D2 dopamine receptors are negatively coupled to adenylyl cyclase and their activation decreases neuronal excitability and neuronal feedback to glutamatergic inputs [153].

Based on the classical hypothesis, MSNs in the direct pathway principally contain D1 dopamine receptors, whereas MSNs in the indirect pathway contain D2 dopamine receptors. Flow of dopamine through these two pathways produces opposite motor effects and thereby modulates activity of output nuclei that is thought to be essential for normal motor function. In fact, when a specific set of striatal neurons are triggered, repression of a subpopulation of pallidal neurons occurs which further clears the tonic inhibition from a specific target motor center, thereby initiating a motor reflex $[59,154]$. The continuous demise of pigmented dopaminergic neurons that occurs in PD decreases striatal levels of dopamine and creates an imbalance between the direct and the indirect basal ganglia pathways. This imbalance leads to over activity of GPi, which results in over-inhibition of the motor thalamus [155]. Over-inhibition of the motor thalamus reduces activity of motor cortex resulting in the onset of parkinsonian syndrome [155] (Figure 1). Recently, numerous levels of cross-talk between direct and indirect pathways have been discovered. As a result, a first level of interaction is represented by the molecular cross-talk between heteromeric D1and D2 receptors $[156,157]$. Activation of D1/D2 heteromers are demonstrated to mediate mechanisms like, increased intracellular $\mathrm{Ca}^{2+}$ levels, activation of calcium/calmodulin-dependent protein kinase II (CaMKII) and release of brain-derived neurotrophic factor (BDNF) $[156,157]$. These mechanisms are prerequisite for striatal physiology and LID $[158,159]$. A series of electrophysiological, biochemical, and anatomical experiments established that the constituents of the ECB system are markedly expressed at different levels in the basal ganglia neural circuitry and thus critically organize motor function and plasticity [160-162]. Dendrites and their presynaptic axon terminals of MSNs that innervate the GPi/e and the SNpr express CB1 receptors $[160,161,163]$. CB1 receptor expression is also found on corticostriatal excitatory glutamatergic terminals as well as in the excitatory extensions from the STN to the GPi/SNpr and SNpc $[160,161,163]$. Recent report is also supporting a role for the malfunctioning of corticostriatal glutamatergic signaling in the occurrence of LID [164]. Compared to the canonical neurotransmitters mentioned above, ECBs function as retrograde synaptic messengers. Retrograde signaling is the primary mode by which ECBs facilitate short and long-term forms of plasticity both at excitatory and inhibitory synapses and interacts with dopaminergic system $[165,166]$. The release and reverse journey of ECBs from postsynaptic neurons activates $\mathrm{CB} 1$ receptors located on presynaptic axons and thus decreases the release of neurotransmitter [167]. In fact, stimulation of presynaptic CB1 receptors on corticostriatal terminals decreases glutamate release $[160,161]$. Similarly, stimulation of CB1 receptors in the output segment of basal ganglia antagonizes both glutamate release from STN 


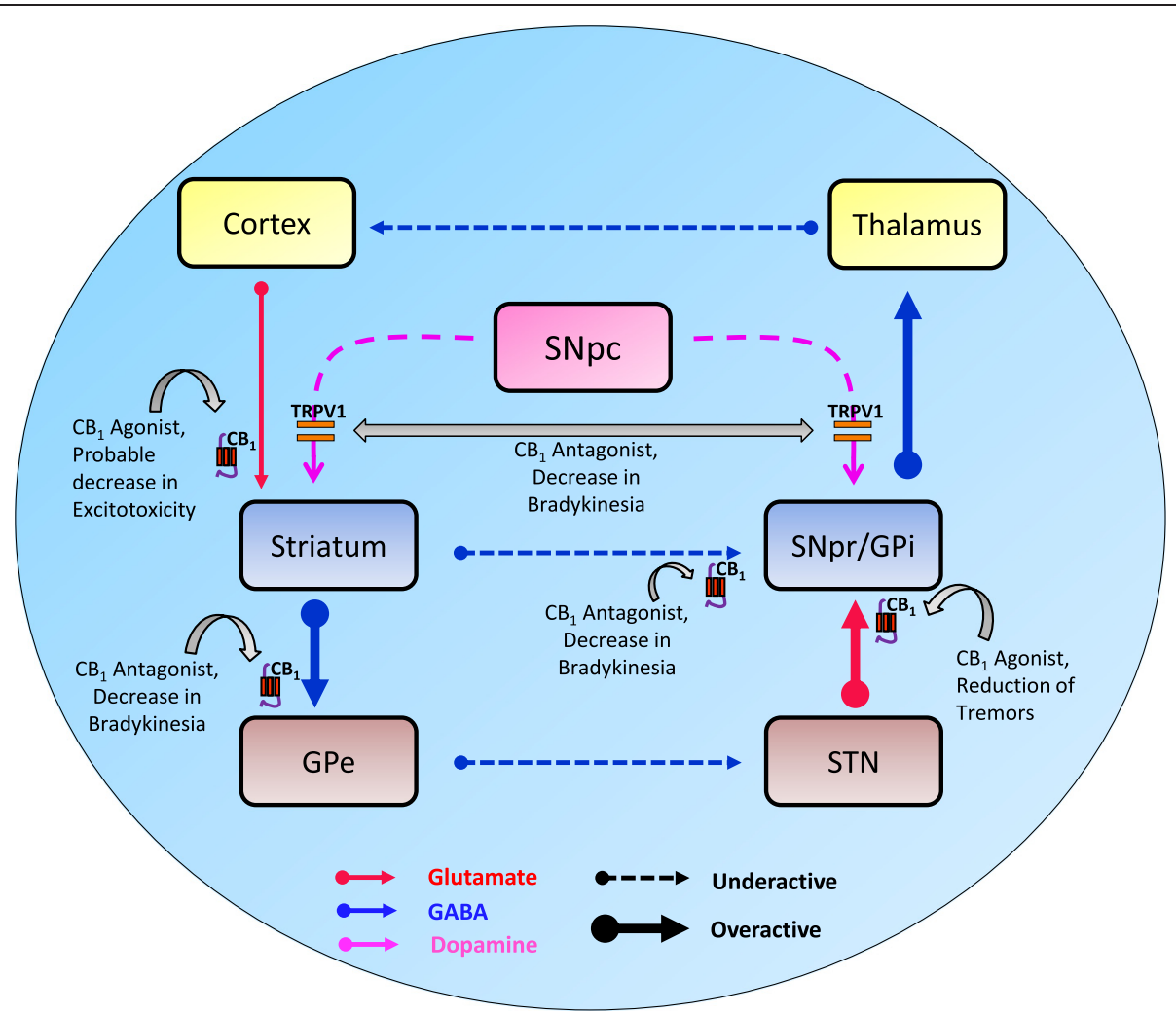

Figure 1 Basal ganglial circuitry in Parkinson's disease (PD) and tentative cannabinoid targets to improve motor disability in PD. Progressive loss of dopaminergic innervation in PD causes overactivity of the indirect (inhibitory) pathway, resulting in excess glutamatergic drive to the GPi and SNpr and diminished activity of the inhibitory GABAergic direct pathway, further disinhibiting the activity of the GPi and SNpr. As output nuclei (GPi and SNpr) use the inhibitory neurotransmitter GABA, this amplified basal ganglia output leads to extreme inhibition of the motor thalamus which acts as a "brake" on motor activity; thus, resulting in the onset of parkinsonian syndrome. The neural circuitry above depicts various possible cannabinoid- based targets (CB1, CB2, and TRPV1 receptors) that can be used to mitigate the symptoms observed in PD. Abbreviations: CB1, cannabinoid receptor 1; TRPV1, transient receptor potential vanilloid 1; GPe, external segment of the globus pallidus; GPi, internal segment of the globus pallidus; SNpc, substantia nigra pars compacta; SNpr, substantia nigra pars reticulata; STN, subthalamic nucleus; GABA,

gamma-aminobutyric acid.

afferents and GABA release from striatal afferents $[160,161,163]$.

Stimulation of presynaptic $\mathrm{CB} 1$ receptors in the GPe may increase local GABA levels by decreasing GABA reuptake from striatal afferents to this nucleus $[160,161,163]$. Dopaminergic signaling is bi-directionally linked to ECB signaling within the basal ganglia. In fact, D1 and D2 dopamine receptors are co-localised with striatal CB1 receptors on GABAergic neurons of striatonigral and striatopallidal pathways $[58,160,161,163,166]$. A tentative interaction between CB1 and D1/D2 receptors at the level of the G-protein/adenylyl cyclase signaling mechanism has been reported $[23,60,168]$. United activation of D1 and CB1 receptors causes a decrease in adenylyl cyclase and a net decrease in the inhibitory activity of direct striatal projection neurons ultimately leading to an inhibited motor response due to increased neuron activity in the SNpr. In contrast, co-stimulation of D2 and CB1 receptors increases adenylyl cyclase $[59,60,169]$ which increases activity in the indirect striatal pathway that activates STN neurons leading to decreased motor activity $[160,161]$. This phenomenon of co-existence of macromolecular complexes composed of functional receptor units with biochemical properties that are different from those of its individual components is called receptor heteromers. Existence of CB1-D2 receptor heteromers was demonstrated using FRET study by Marcellino. et. al in 2008 [170]. In another study it was proposed that just by co-expressing CB1 and D2 receptors is adequate to induce stimulation of adenylyl cyclase in response to CB1 receptor activation [171]. The reasons for dissimilarities between these studies remains to be resolved, but all of these studies demonstrate that activation of CB1-D2 receptor heteromer can have completely opposite effects than activation of the individual receptors. Recent electron microscopy analysis with double labeling in the ventral striatum has established the presence of overlapping subcellular distributions of CB1 and D2 receptor immunoreactivities both at 
the pre and postsynaptic levels [172], providing significant support for the presence of CB1-D2 receptor heteromers in the striatum. Although some reports have suggested heterodimerization of CB1 and D2 receptors, [170,173] the functionality of these heteromers in striatal glutamatergic terminals has not been confirmed [70,174]. Apart from, CB1-D2 receptor heteromers, recently with the aid of biochemical and biophysical studies CB1-CB2 receptor heteromers is reported in nucleus accumbens and globus pallidus [175]. Typical characteristic feature observed with CB1-CB2 receptor heteromers is that, CB1 receptor antagonists blocks the effect of $\mathrm{CB} 2$ receptor agonists and, conversely, CB2 receptor antagonists blocks the effect of $\mathrm{CB} 1$ receptor agonists thus demonstrating a bidirectional phenomenon of cross-antagonism [175]. These heteromers may describe preceding conflicting results and may serve as therapeutic targets. Recent evidence suggests that dopamine modulates the activity of $\mathrm{SNpc}$ neurons not only by conventional dopamine receptors, but also by $\mathrm{CB} 1$ receptors, possibly via Narachidonoyl-dopamine [176]. In addition to localization of CB1, the presence and functional role of TRPV1 on dopaminergic nigral neurons and their role in modulating synaptic transmission within the SNpc have also been determined [177]. TRPV1 immunostaining was observed in fibers and post-synaptically in striatal neurons [120], however the specific anatomical uniqueness of these TRPV1 expressing components has not been examined. It has been recently presented that CB1 and TRPV1 receptors decrease and increase the glutamate release from gliosomes [178] signifying a possible association of TRPV1 receptors in the regulation of cortical activity and plasticity. Additionally recent studies that establish the existence of different forms of TRPV1-mediated synaptic plasticity in the striatum [179], the presence of dissimilar forms of TRPV1-mediated cortical plasticity is highly probable, although this remains to be confirmed. Based on these reports, it is speculated that ECBs may critically regulate physiological functioning of the basal ganglia neuronal circuit. Additionally, the existence of elements of the ECB system in different neural circuits and their direct interaction with GABAergic, glutamatergic, and dopaminergic signaling systems makes these components an ideal nondopaminergic target for PD.

\section{Consequences of corticostriatal plasticity in PD: role of endocannabinoids}

Synapses, particularly those in the striatum, sustain long-lasting morphological and functional modifications after continuously activating neuronal pathways [158]. Synaptic plasticity seems to play an important role in the dynamics and development of a neuronal circuit in the corticostriatal region, particularly motor learning. Continuous stimulation of striatal synapses of MSNs in the corticostriatal pathway elicits both long-term depression (LTD) and long-term potentiation (LTP) of synaptic transmission efficacy. Activation of dopamine receptors is a prerequisite for both LTD and LTP at corticostriatal synapses $[158,166]$. This phenomenon is observed to be impaired in both the striatum and the motor cortex of patients with PD as well as in experimental models of PD [180,181]. In contrast, ECBs are actively involved in the formation of LTD synapses that connect striatal and cortical neurons and therefore plays a vital role modulating the dynamics of the striatal neural circuit. Elevated intracellular calcium, stimulation of D2 receptors and activation of striatal MSNs are reported to discharge ECBs such as AEA $[23,28,59]$. Hence, it is speculated that release of AEA from postsynaptic neurons under such circumstances might act as retrograde messenger stimulating presynaptic CB1 receptors and initiating long-lasting depression of excitatory glutamatergic transmission [182-184]. However, it has been hypothesized that MSNs of the direct and indirect striatal pathways might manifest diverse synaptic properties [174]. In particular, satisfactory release of ECBs requires ECBmediated LTD which is limited only to MSNs in the indirect-pathway [174]. The role of ECBs in the control of LTD of MSNs is an important topic of discussion having great consequence on the direct/indirect pathway [59]. ECB-dependent synaptic plasticity of MSNs could depict a synaptic mechanism for the formation of persistent drug-related behaviors [59]. In agreement with this view, it has been witnessed in a mouse model of cannabinoid tolerance that continuous activation of the ECB pathway impairs LTD in MSNs [185]. Synapses between MSNs in the indirect-pathway are abolished in experimental models of PD $[186,187]$. This deficiency can be recovered by a D2 dopamine receptor agonist such as quinpirole or by URB597, an inhibitor of FAAH [174]. Administering URB597 and quinpirole significantly decreases catalepsy and increases locomotor activity in experimental models of PD [174]. This result indicates a direct interrelationship between recovery of ECBmediated synaptic plasticity at corticostriatal synapses and improvement in PD motor symptoms. Also, within the striatum, sub-class of GABAergic interneurons that are observed to produce NO [59] and cholinergic interneurons are found to express CB1 receptors [188]. In line with these reports various electrophysiological experiments have also demonstrated that inhibitors of NOS avert induction of LTD $[189,190]$. Loss of LTD expression at glutamatergic striatal synapses on both the classes of MSNs has been reported to cause LID [189]. Therefore, damage to ECB-dependent striatal LTD at corticostriatal synapses may contribute to the abnormal activation of this specific neuronal circuit culminating in over stimulation of GPi and subsequent 
over-inhibition of the motor cortex leading to the initiation of parkinsonian syndrome.

\section{Therapeutic availability of cannabinoids for motor symptoms in PD}

Cannabinoids were previously reported to only produce behavioral patterns such as catalepsy and hypolocomotion in experimental animals. Due to these peculiar behavioral effects of cannabinoids, their therapeutic use for alleviating bradykinesia, rigidity, and other hypokinetic symptoms typical of PD is limited [148,191,192]. These effects lead to an array of studies that investigated various facets of cannabinoids on motor symptoms in PD. The evidence obtained in different animal models and in clinical trials produced a basis for the involvement of cannabinoids in motor behaviors. As cannabinoids lack specificity of binding to the desired target, the data obtained varied in specific motor effects of cannabinoids but it also opened new doors for their clinical utility. The evidence that ECBs such as AEA not only bind to CB1 receptors but also bind to TRPV1 receptor, has diverted the focus of research into novel mediators that regulate motor effects of cannabinoid [193]. Therefore, the presence of ECBs in different regions of the basal ganglia circuitry along with the polymorphous nature of cannabinoidmediated mechanisms makes it a complex physiological phenomenon eliciting behavioral effects. Many experiments aimed at outlining the effects of CB1 agonists and antagonists and their potential utility in PD (Figure 1), have produced inconsistent data, as there are many complex responses produced by dopamine and its interaction with different cannabinoid mechanisms [193].

Since CB1 receptors are highly expressed in both D1 and D2 receptor containing MSN, and they antagonize D1 and D2 receptor mediated behaviors, mounting evidences have suggested the involvement of endocanabinoid system in dyskinesia [58]. This is the central motive to hypothesize CB1 receptor as a therapeutic target to regulate the imbalance of glutamatergic or GABAergic neurons in PD and dyskinesia [194]. There is also a report that ECBs and cannabinoid agonists decrease dopamine reuptake by inhibiting dopamine transporters [195] and hence may have applications for fine tuning the striatal neuronal network involved in dyskinesia [196]. Initial studies concerning motor behavior involved investigating the effect of the cannabinoid agonists $\mathrm{CP}$ 55,940 and WIN-55,212-2 on rotational behavior induced by the D1 dopamine receptor agonist SKF 38393 in 6-OHDA model of PD [136]. Rotational behavior induced by SKF 38393 was mitigated by both cannabinoid agonists, but the same response was not observed when they were tested with the D2 agonist quinpirole. In contrast, WIN-55,212-2 decreased the effects of the D2 agonist, but not those of a D1 agonist in reserpinized rats [197]. Although there was a discrepancy in the effects elicited by the cannabinoid agonist on different dopamine agonists, these data demonstrate that cannabinoid agonists antagonize the effect of dopaminergic drugs. Consistent with the pharmacological model, the cannabinoid receptor antagonist rimonabant (SR 141716A) was found to boost the locomotive effects of quinpirole in normal and reserpinized rats and also increased the locomotor activity in mice pre-exposed to 9-THC $[21,23,198]$. However, paradoxical results were obtained by the SR 141716A in primate models [168]. Rimonabant was found to be unsuccessful [131] to antagonize motor deficits in 1methyl-4-phenyl-1,2,3,6-tetrahydropyridine (MPTP)-intoxicated primates [130], although these experiments used different primate species. Also, in a confined clinical trial, rimonabant had no antiparkinsonian effects in combination with levodopa [151].

Blocking CB1 receptors may be effective only in particular circumstances, such as when low doses of CB1 receptor antagonists are used, when patients do not respond to dopamine therapy, or when they are in progressive phases of the disease [199-201]. Although the data obtained were from drugs with different specificities and in different animal models, these results indicate an indecisive effect of CB1 antagonists on parkinsonian symptoms. This result indicates a central advantage, as it may provide a novel anti-parkinsonian agent useful for circumstances in which classic dopaminergic replacement therapy is futile. The synergism of antiparkinsonian effects caused by cannabinoid antagonists with dopaminergic drugs to stimulate movement suggests that cannabinoid agonists may antagonize the actions of dopaminergic drugs, including LID. Long-term levodopa therapy for PD generally results in variations in motor responses called dyskinesias or abnormal involuntary movements (AIM) $[202,203]$. Few evidences supporting this hypothesis are cannabinoid agonist, WIN-55,212-2 that produced antidyskinetic effects in rodents [204], and nabilone that reduced dyskinesia in primate models and patients $[149,205]$. The effect of CB agonist depends on the fact that $\mathrm{CB} 1$ receptors are expressed on the presynaptic terminals of the striatonigral and striatopallidal neurons (GABAergic neurons), as well as on the presynaptic terminals of corticostriatal neurons (Glutamatergic neurons), and are thought to exert a tonic inhibitory effect via retrograde signalling from postsynaptic neurons (Figure 1). Therefore, it can be proposed that cannabinoid agonists may decrease dyskinesia by antagonizing the effects of dopaminergic drugs. Nonetheless, some evidence does not match the above hypothesis, as the selective cannabinoid antagonist rimonabant decreases LID in MPTP-treated marmosets [130]. In contrast, another study reported the ineffectiveness of the CB1 antagonist CE-178253 in parkinsonian rhesus monkeys 
[206]; thus, indicating a tentative role of animal species and behavioral outcome. However, clinical trials failed to reproduce the same effect using a cannabis extract; thus, questioning the true use and activity profile of cannabinoids $[150,163]$. In contrast, another study demonstrated amelioration of parkinsonian symptoms and dyskinesia after discontinuing use of cannabis for months with no clear explanation [148]. In conclusion, it can be stated CB1 antagonists seem to have antiparkinsonian effects (antidyskinetic effect), whereas activities of CB1 agonists appear to be highly ambiguous [193].

A very recent study by Mathur et. al; have reported the involvement of corticostriatal ECB-LTD in the development of LID [166]. Another report related to this study, demonstrated that, treatment with L-DOPA causes expression of ECB-LTD only in non-dyskinetic parkinsonian rats and not in dyskinetic rats [189]. Furthermore decreased levels of cGMP signaling in the brain were also observed in hemiparkinsonian rats with LID [207]. Specific inhibition of phosphodiesterase- 5 by zaprinast and UK-343664 was found to restore ECBLTD in these dyskinetic rats and mitigate the incidence of dyskinetic behaviors [189]. Thus, restoring ECB-LTD can be considered as a potential target for therapeutic intervention in PD. Apart from dopaminergic neurons, striatal serotonergic neurons are capable of using L-DOPA to release dopamine which contributes towards LID [208]. Agonist for serotonergic neuron autoreceptors (5-HT1a/b) are been speculated to abate corticostriatal glutamatergic release and thus show efficacy in mitigating LID [209]. This data agrees with the study done my Picconi et. al, wherein only L-DOPA treated rodents having LID elicit loss of ECB-LTD. Lastly, new data has suggested a role for the regulator of G-protein Signaling 4 (RGS4) protein in modulating ECB production in MSNs of indirect pathway. RGS4 is as a strategic link between D2/A2A signaling and ECB mobilization pathways. It was found that inhibition of RGS4 was observed to reinstate ECB-LTD in the presence of a D2-antagonist (sulpiride), while RGS4 deficient 6-OHDA denervated mice were resistant to some features of motor dysfunction typical of parkinsonism [210]. Based on these results, RGS4 can serve as a nondopaminergic target to treat PD. Cannabinoidmediated mechanisms in the striatum play a crucial role regulating dopamine-induced motor behaviors. Activating CB1 receptors increases neuronal activity in $\mathrm{SNpc}$ [146]. This finding is opposed by a report wherein ECBs such as AEA and other related congeners acting through postsynaptic TRPV1 receptors may diminish nigrostriatal dopaminergic cell activity [122]. Nevertheless, other authors have stated a surge in dopamine release after stimulating TRPV1 receptors in the SNpc [177,211]; however, this improvement may be facilitated by TRPV1 receptors located in glutamatergic terminals in the SNpc rather than by receptors located in dopaminergic terminals.

Presynaptic CB1 receptors in corticostriatal terminals modulate discharge and uptake of glutamate; thus, causing a decrease in glutamate-mediated excitation in MSNs (Figure 1) [212]. Based on interacting dopaminergic mechanisms and their corresponding regulatory status, modulating glutamate transmission might result in different motor effects. Furthermore, coupling postsynaptic CB1 receptors with G-proteins has contrasting regulatory effects on D1 and D2-mediated responses, such as negative and positive regulation, respectively [168]. It is unclear whether the striatal reduction is due to a lesion or by an increase in ECBs as a compensatory mechanism [213] with respect to changes occurring after dopaminergic loss in the cannabinoid system [204]. Correspondingly, CB1 receptor binding also changes with the demise of dopaminergic neurons $[129,213]$. Some modulation by cannabinoids may occur due to the changes produced by dopamine deprivation during the early and preclinical stages of the disease, and this modulation becomes incompetent and motor symptoms develop as the disease advances [160]. Regardless of the controlling position of the striatal cannabinoid system in $\mathrm{PD}$, pre and postsynaptic machinery mutually result in precise effects on isolated projection neurons contributing to the drug induced-behavioral changes. Thus, numerous factors intercede in the striatal activities of cannabinoid agonists and antagonists to regulate their effects on motor responses to dopaminergic drugs. The effects of CB1 agonists to attenuate LID may be facilitated by striatal machinery where the cannabinoid system is controlling a weakened dopamine system that pushes errors of activity (mistake-proofing) and discharges involuntary movements. Glutamate/NMDA antagonists may help to reinstate normal responses to levodopa with attenuation of dyskinesias [214-216] by decreasing the activity of glutamatergic projections, an action similar to CB1 agonists in the striatum.

Both the cannabinoid actions have been established by electrophysiological studies on the discharge of GABA and glutamate, although their communication may lead to specific synaptic transmission effects, and these effects remain unspecified. In addition, it is unknown whether one of these mechanisms dominates after dopaminergic loss to elicit a clear behavioral response, as they are functionally contrasting. Hallmark features of cannabinoids to increase GABA and reduce glutamate transmission strongly impede neuronal activity in GPe and result in catalepsy [217]. In line with this report, neurons containing D1 receptors participate in the motor depressant effects under the influence of presynaptic CB1 receptors while interaction of neurons containing D2 receptors with postsynaptic $\mathrm{CB} 1$ receptors are thought to 
mainly facilitate the cataleptogenic effects of cannabinoids [218]. Depleting dopamine levels significantly increases the levels of ECBs in GPe [21]. So, CB1 antagonists, via mechanisms in the indirect pathway, may synergize with the antiparkinsonian effects of levodopa. Moreover, CB1 receptors inhibit GABA release on presynaptic neurons in the STN [219], which may add to this synergism. Consequently, the cannabinoid activities in these areas of the indirect pathway are well-matched with the antiparkinsonian properties of $\mathrm{CB} 1$ antagonists and the antidyskinetic effects of $\mathrm{CB} 1$ agonists. The main caution is that these activities cannot be secluded from other vital cannabinoid actions in additional basal ganglia circuits. Existing data suggest no adequate proof to establish the mechanisms overriding the behavioral responses of cannabinoids administered systemically in a parkinsonian background. In addition, cannabinoid drugs with comparable abilities have elicited diverse motor responses even when they display high CB1 receptor specificity. Despite experimental disparities, incongruous evidence has been obtained from pre-clinical and clinical models, with drug doses acting on numerous sites of basal ganglia, suggesting a highly intricate mechanism wherein cannabinoids might bind to other locations and act through other mechanisms besides the extensive CB1 regulation of corticostriatal synapses controlling motor effects [193]. Crucial data have appeared from experiments suggesting that ECBs bind to other than CB1 receptors $[220,221]$. Thus, the practical role of additional binding sites becomes essential to the mechanisms responsible for cannabinoid effects [222].

Findings by Morgese and colleagues described the effects of cannabinoids via binding to dissimilar receptors in a LID parkinsonian model of rat [223]. The study involved dopamine-denervated rats, wherein increased levels of AEA were attained by administering the URB597. URB597 had noteworthy effects on levodopainduced AIMs only if URB597 was co-administered with capsazepine, a TRPV1 antagonist. These results demonstrate that ECB binding to the TRPV1, antagonizes their antidyskinetic effects mediated presumably by binding to CB1 receptors [223,224]. The favorable effects of CB1 receptor antagonists against bradykinesia in PD may be due to the hyperkinetic ability displayed by blocking TRPV1 receptors (Figure 1). This hypothesis is based on the suggestion that stimulating TRPV1 receptors present on nigrostriatal dopaminergic neurons [117] impedes the synthesis and release of dopamine in striatal dopaminergic terminals [122]; therefore, their pharmacological blockade may produce the opposite effect and improve the motor inhibition characteristic in PD. Nevertheless, this approach might have a disadvantage in terms of a potential clinical application for TRPV1 receptors to lessen bradykinesia in PD, as advanced phases of PD are accompanied by death of nigrostriatal dopaminergic neurons and loss of TRPV1 receptors [225]. Multiple reports documenting different results nurture questions regarding the receptor binding profile of cannabinoid drugs that elicit contradictory results through frequent testing in animal models and clinical trials. AEA is one of the most studied ECBs. AEA is a partial agonist at the $\mathrm{CB} 1$ receptor and also binds to TRPV1 $[220,121,226]$ as a partial agonist, by which few of its numerous pharmacological effects may be facilitated [227]. According to an electrophysiology study, vanilloid receptors control glutamate signaling to dopaminergic neurons in the substantia nigra [211]. Moreover, there is mutual expression of CB1 and TRPV1 receptors in areas of the basal ganglia, and preceding studies [228] have shown their functional communication with dopaminergic neurons. Interestingly, oleoylethanolamide (OEA) also augments the effect of AEA by acting on TRPV1; furthermore it decreases LID at doses that do not change motor behavior in the mouse model of dyskinesia [229]. This result is in agreement with another report wherein, capsaicin, a specific TRPV1 agonist, eliminated both the increase in molecular markers of dyskinesia and the antidyskinetic effects of OEA [196]. The communication between CB1 and TRPV1 receptors appears to be principally controlled by some key molecules such as FAAH [230]. The metabolic activities of FAAH and AMT in the striatum are abated in 6-OHDA lesioned rats [213]. Therefore, it is conceivable that motor variations can be initiated by potentiating AEA activity using an FAAH inhibitor. In comparison to AEA, WIN-55,212-2, a CB1 agonist with inhibitory effects on the TRPV1 receptor [231], has analogous effects on AIMs as those induced by increasing AEA by co-administration of a TRPV1 antagonist, as AEA is a partial agonist of both receptors. Also, treatment with a CB1 antagonist did not reverse the antidyskinetic effects of elevated AEA. Hence, the antidyskinetic effects of ECBs may be mediated by binding to receptors other than $\mathrm{CB} 1$. Therefore more than a few inferences can be drawn from these data. First, the binding locations facilitating the AEA induced motor responses remains to be established; thus, ECB receptors involved in motor activities consist of vanilloid and others anonymous receptors [232]. Second, the motor responses for the CB1 receptor agonist WIN-55,212-2 are also influenced by its activity at TRPV1 and other cannabinoid or additional cannabinoid sites. Lastly, mechanisms facilitated by cannabinoid binding to TRPV1 and possibly other vanilloid receptors are associated with motor responses to levodopa [193] and also suggest TRPV1 as a potential therapeutic target for PD which is devoid of dyskinesia [194].

\section{Neuroprotective prospective of cannabinoids in PD}

Substantial bulk of information has been accumulated that suggests a strong potential for cannabinoid compounds 
that could provide neuroprotection against acute or chronic neurodegenerative disorders (Table 1) [132,138,233-236]. This information is mostly relevant considering the postmitotic features of neuronal cells, in which repair processes are particularly difficult after several types of brain injuries. However, cannabinoids have also participated in the regulation of neurogenic reactions in definite structures of the brain $[186,237]$. The neuroprotective ability of cannabinoids has been displayed against acute neuronal degeneration as shown by diverse in vitro and in vivo models that reproduce cytotoxic events causing cell death $[235,238]$. Additionally, cannabinoids are also documented to elicit neuroprotection in progressive neurodegenerative pathologies involving mitochondrial dysfunction, inflammation, oxidative stress, and excitotoxicity [239-241]. Both $\mathrm{CB} 1$ and $\mathrm{CB} 2$ receptor are reported to be induced in response to brain damage and/or inflammation [132,239]. For instance, CB1 receptors were up-regulated after experimental stroke [242,243], and in response to excitotoxic stimuli in newborn rats [244]. As compared to CB1 receptor, most of the pertinent data was obtained with CB2 receptors owing to their negligible presence in brain $[239,245,246]$. CB2 receptors have been demonstrated to be modulated in various neurodegenerative diseases preferentially involving astrocytes and microglia in disease pathology of stroke [247], Huntington's disease (HD) $[115,248]$, in patients with Down's syndrome, Multiple sclerosis (MS) and Amyotrophic lateral sclerosis (ALS) [249-251], in the senile plaques of patients with Alzheimer's disease (AD) [105] and in pre-clinical model of AD and MS in rats $[252,253]$. Agonists of CB2 receptor protect against neuronal damage in pre-clinical models of focal ischemia [254], AD [255], HD [247,248], MS [253], and ALS [256]. From all these studies it was anticipated that neuroprotection conferred by agonists at CB2 receptors were associated to the presence of these receptors in glial components. However recent report has established that the activation of $\mathrm{CB} 2$ receptors located in neurons may also be defensive against remote-axotomy-induced apoptosis, an outcome that involves the activation of PI3K/Akt signaling [257]. This displays that various cannabinoid elements that are altered in response to neurotoxic insults in different experimental models of neurodegeneration can be targeted to develop a tentative therapeutic. However, the degree and accuracy of these alterations depend on several parameters, such as animal species, age, type and severity of injury, and mechanisms activated in the cell [258].

Therapeutic role of cannabinoids in oxidative stress in PD Augmented oxidative stress has long been linked with PD [259]. Reactive oxygen species (ROS) derived from mitochondria are involved in PD pathology as weakened mitochondrial function and increased oxidative markers cause neuronal injury in PD patients [260]. Cellular and animal studies have emphasized a role for superoxide anion produced by microglial NADPH oxidase in augmenting the demise of dopaminergic neurons in PD [261]. Recently low levels CB1 receptors have been detected on mitochondrial membrane hinting towards a direct relationship between CB1 receptor and mitochondrial functions in the brain [262]. The phenolic ring moieties in cannabinoids [263] have been found to display antioxidant activity and guard against glutamate-induced neurotoxicity in a cellular model [264]. More recent evidence in rodents indicates that cannabinoid treatment might protect against neuronal damage in diabetic neuropathy [265] and the cognitive impairment induced by experimental sepsis [266]. One of the latest studies documented the protective effects of synthetic cannabinoids on paraquat-induced generation of mitochondrial ROS [267]. Taken together, these discoveries support the hypothesis that treatment with cannabinoids having antioxidant effects may modulate mitochondrial ROS production [56] in the PD brain. Apparently, cannabinoids can also quench ROS generated by microglial NADPH oxidase in the extracellular space that cause neuronal damage, but this hypothesis has not been tested yet. A study in C57BL/6J mice with cisplatininduced nephropathy established that the antioxidant cannabidiol diminishes the increase in NADPH oxidase expression and decreases markers of inflammation, oxidative stress, and cell death in kidneys [268]. The mechanism by which cannabidiol acts to reduce NADPH oxidase expression and inhibit oxidative injury within the PD brain has yet to be confirmed but it seems to act through mechanisms independent of CB1 or CB2 receptors [44].

This finding is specifically important, as hypokinetic activity of cannabinoids that stimulate CB1 receptors signifies a drawback for PD because such compounds acutely augment rather than diminish motor disability [138]. Consequently, major efforts are being focused at exploring cannabinoid molecules that deliver neuroprotection through their antioxidant properties and which specifically activate CB2 receptors and may even antagonize CB1 receptors to provide additional benefits for alleviating symptoms such as bradykinesia [44]. Nonetheless, other evidence also supports the hypothesis that cannabinoids may confer protection against PD pathology in rodent models due to their antioxidant properties. Synthetic cannabinoids with antioxidant abilities protect against pathological features encountered in rats injected with 6-OHDA [225,269]. AM404 and cannabidiol, which have validated anti-oxidant activity in cellular models but slight to no affinity for CB receptors [270], have established neuroprotective effects. Although the direct effects of cannabinoids on indicators of oxidative stress were not measured, treatment with cannabinoid did avert a decrease in cytosolic mRNA levels of endogenous 
Table 1 Summary of the pharmacological effects demonstrated by cannabinoids in various model of PD and other neurodegenerative diseases

\begin{tabular}{ll}
\hline Compound & Model \\
\hline Oleoylethanolamide (OEA) & 6-OHDA model of PD in mice \\
& \\
Oral Cannabinoid Extract (OCE) & $\begin{array}{l}\text { A Class I double-blind crossover study } \\
\text { in dyskinetic patients }\end{array}$ \\
Cannabis administration via smoking & $\begin{array}{l}\text { Open-label observational study in } 22 \\
\text { PD patients }\end{array}$
\end{tabular}

WIN-55,212-2

OEA and Palmitoylethanol-amide (PEA)

WIN-55,212-2 and HU-210

$\mathrm{THC}$

THCA, THC and CBD

WIN-55,212-2

WIN-55,212-2

WIN-55,212-2 and HU-210
(9)-THCV

(9)-THCV

AM251 and HU210

WIN-55,212-2

Rimonabant

JWH015

Adenoviral vector enforced expression of the CB1 receptor
L-DOPA-induced motor fluctuation model of PD

LPS-induced neuroinflammation in rat

Intranigral injection of LPS in rats

$\mathrm{MPP}^{+}$, lactacystin and paraquat induced neurotoxicity in SH-SY5Y cells

$\mathrm{MPP}^{+}$induced cytotoxicity to mice mesencephalic cultures

L-DOPA-induced (AIMs) in the 6-OHDA injected rat

PSI-induced cytotoxicity in PC12 cells

MPTP model of PD

Unilateral 6-OHDA lesions in rats

LPS model of PD in mice

Levodopa-induced dyskinesia in a rat model

MPTP model of PD

Unilateral 6-OHDA lesions

MPTP model of PD in mice

R6/2 mouse model of $\mathrm{HD}$

3NP model of HD in rats
Activity profile
OEA reduces dyskinetic symptoms and
molecular markers of dyskinesias including

Ref.

striatal overexpression of FosB and

phosphoacetylation of histone 3

OCE was ineffective for treating levodopa-

induced dyskinesias in patients with PD

Cannabis was found to improve tremor, rigidity and bradykinesia in $\mathrm{PD}$ patients.

Also, sleep and pain scores were also

improved

WIN-55,212-2 significantly reduced AIMs

to L-DOPA in 6-OHDA-lesioned rats by

modulating DARPP-32 and ERK $1 / 2$

phosphorylation in striatal neurons

OEA and PEA inhibited oxidative and nitrosative stress by reducing LPS-induced

NFkB expression and subsequent release of proinflammatory mediators

WIN-55,212-2 and HU210 increased the survival of nigral neurons, inhibited activation of $\mathrm{NADPH}$ oxidase, ROS production and production of proinflammatory cytokines

THC exhibited neuroprotective effect against all toxins probably by activation of PPAR- $\gamma$ receptors

All cannabinoids exhibited anti-oxidative action. THC and THCA protected dopaminergic neurons

WIN-55,212-2 ameliorated L- DOPA induced AIMs

WIN-55,212-2 protects PC12 cells from

PSI-induced cytotoxicity, Inhibits cytoplasmic accumulation of parkin and a-synuclein

WIN-55,212-2 and HU210 increased survival of DA neurons in the SN, reduced expression of proinflammatory cytokines and improved motor function

(9)-THCV attenuated the motor inhibition

(9)-THCV decreased microglial activation and protected nigral TH neurons

HU210 significantly reduced certain subtypes of AIMs while, AM251 had no effect on AIMs

WIN-55,212-2 protected TH neurons in the SN

Rimonabant improved motor behavior

JWH015 reduced MPTP-induced microglial activation

Vector-enforced expression of CB1 receptor causes re-expression of BDNF and cures neuropathological deficits

CBD protected striatal neuron by completely reversing 3NP-induced reductions in GABA contents and mRNA levels for SP, NSE and SOD-2 


\section{Table 1 Summary of the pharmacological effects demonstrated by cannabinoids in various model of PD and other neurodegenerative diseases (Continued)}

\begin{tabular}{ll}
\hline CBD & $\begin{array}{l}\beta \text {-amyloid-induced model of AD } \\
\text { rats with or without GW9662 }\end{array}$ \\
JWH-133 & ABPP/PS1 genetic model of AD \\
Sativex ${ }^{\circledast}$ & Human tau overexpressing mice \\
MDA7 & model of AD \\
& A -induced model of AD in rats
\end{tabular}

CBG

HU210

ACEA, HU-308 and CBD
3NP model of HD in mice

PC12 cells model of HD expressing mutant huntingtin

Malonate induced model of HD in rats
Presence of GW9662 was able to significantly

[280]

block protective effects of $\mathrm{CBD}$ on reactive

gliosis and on neuronal damage. CBD also

induced hippocampal neurogenesis

JWH-133 lowered microglial activity, decreased expression of pro-inflammatory cytokines and tau hyperphosphorylation

Sativex ${ }^{\circledR}$ decreased gliosis and generation of free radical in hippocampus and cortex

MDA7 mitigated the expression of microglia and astroglial markers, reduced the secretion of interleukin-1 $\beta$, diminished the increase of $C B 2$ receptors, promoted clearance of $A \beta$ and restored synaptic plasticity, cognition, and memory

CBG improved motor deficits and preserved striatal neurons. CBD also decreased reactive gliosis and upregulated antioxidant defenses

HU210 increased cell survival, by cyclic adenosine monophosphate and extracellular signal-regulated kinase mechanisms

Activation of CB2 receptor diminished reactive gliosis and subsequent release of proinflammatory cytokine

Abbreviations: DA, dopamine; THCA, Tetrahydrocannabinolic acid; CBD, cannabidiol; MPP+, 1-methyl-4-phenylpyridinium; AIMs, abnormal involuntary movements; SN, substantia nigra; 9-THCV, tetrahydrocannabivarin, THC, Tetrahydrocannabinol TH, tyrosine hydroxylase; LPS, lipopolysaccharide ; 6-OHDA, 6-hydroxydopamine; PSI, proteasome inhibitor; 3NP, 3-nitropropionic acid; HD, Huntington's Disease; SP, substance P; NSE, neuronal-specific enolase; SOD, superoxide dismutase; AD, Alzheimer's disease; MDA7, 1-((3-benzyl-3-methyl-2,3-dihydro-1-benzofuran-6-yl) carbonyl) piperidine; CBG, Cannabigerol.

anti-oxidant copper-zinc superoxide dismutase following 6-OHDA intoxication [269].

Supplementary mechanisms related to the direct improvement of endogenous antioxidant enzymes involve the activation of the anti-oxidant transcription factor nuclear factor erythroid 2-related factor 2 (Nrf-2) [8]. In a recent report, cannabidiol was found to up-regulate the transcription of Nrf-2 in BV-2 microglial cells [271]. Cannabidiol also increased the subsequent downstream enzymes including heme oxygenase-1, glutathione Stransferase, glutathione S-transferase peroxidase, NAD (P)H:quinone oxidoreductase and glutamate-cysteine ligase, which play central role in providing defence against cytotoxic and electrophile-induced oxidative stress [272]. However, more robust data are needed to support the antioxidant capacity of cannabinoids (Figure 2) in animal models. Nonetheless existing evidences does suggest that cannabinoids may serve as promising antioxidant therapy for treating PD.

\section{Therapeutic role of cannabinoids in neuroinflammation in PD}

Neuroinflammation is a crucial pathological factor responsible for the demise of dopaminergic neurons in PD. Glial cells play a key role in neuroinflammation; elevated levels of activated microglia are found in the substantia nigra of patients with PD compared to brains of control subjects [90]. Lipopolysaccharide administration to mice increases CB2 receptor expression in nigral cells, and stimulation of these receptors shelters dopaminergic neurons from microglia-induced inflammation [273]. A limited amount of research has been performed pertaining to the anti-inflammatory properties of cannabinoids, but recent evidence substantiates that some cannabinoids, predominantly CB2 receptor ligands, may attenuate the neuroinflammation associated with PD $[82,103,269,274]$. Lesioned sites are observed to express CB2 receptors on astroglial cells [234]. Consequently, it is likely that these receptors augment the generation of neurotropic factors or metabolic substrates, such as lactate and ketone bodies, but these prospects has not been established yet. In a recent study utilizing intracerebral injection of 6-OHDA to induce parkinsonian symptoms in rats showed that the agonistic activity at $\mathrm{CB} 2$ receptors may offer neuroprotection. In this study, the 6-OHDA neurotoxin was injected into the medial forebrain bundle of rats, causing a substantial decline in the number of catecholaminergic neurons and inducing neuroinflammation [275]. In another study, daily pre-treatment of rats with 9-THC and cannabidiol for 2 weeks, followed by 6OHDA injection, abated loss of dopaminergic neurons [225]. Using comparable in vivo methods, Garcia et al. 


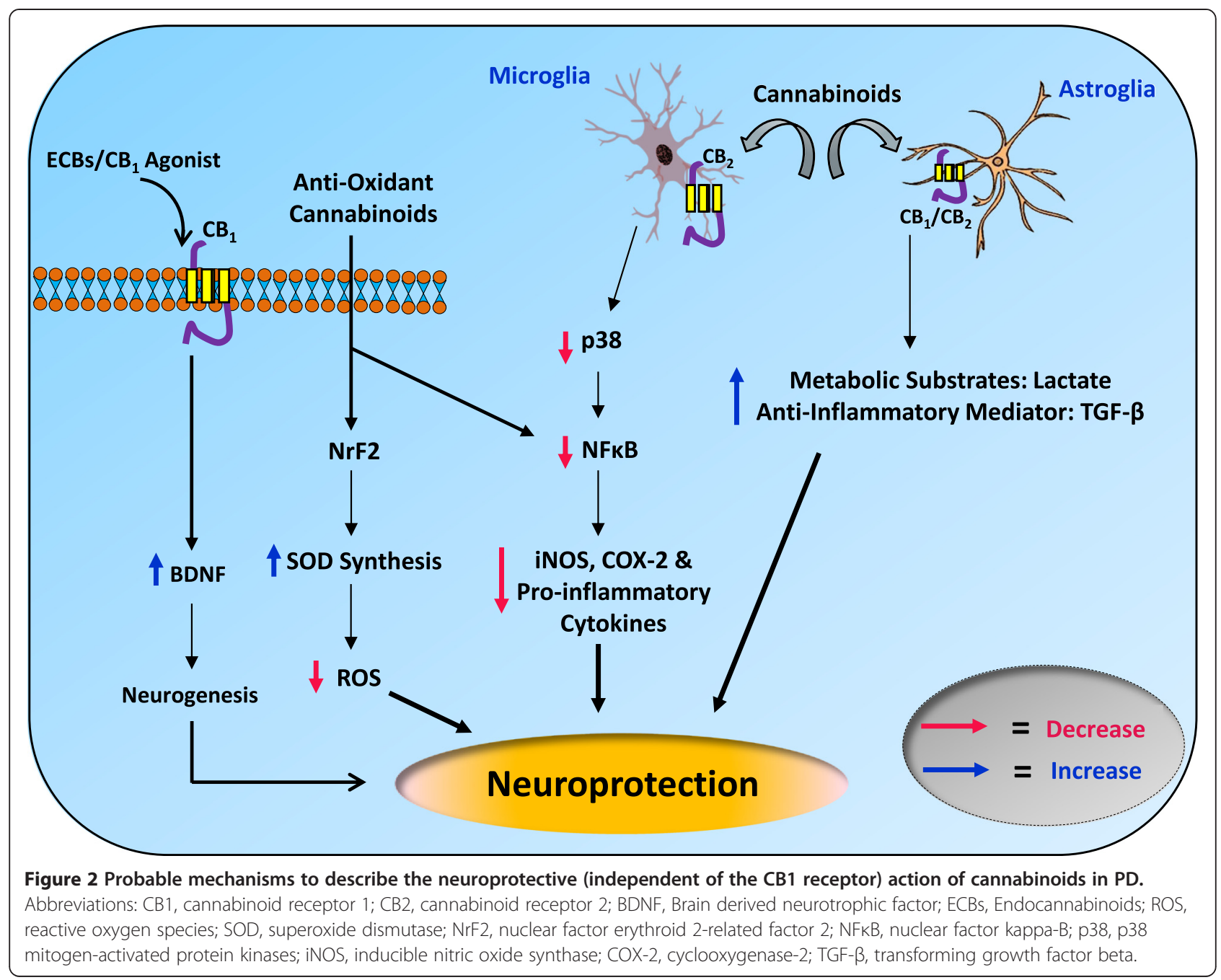

established that treatment with synthetic the CB2 receptor agonist HU-303 displayed neuroprotective effects [269]. Transgenic rodents overexpressing the CB2 receptor were observed to mitigate demise of dopaminergic neurons and alleviate motor impairment following experimentally induced PD [113]. Similarly, injection of WIN-55,212-2 to rats for 4 weeks was found to decrease the number of activated microglia in the hippocampus and dentate gyrus as well as to reduce the mRNA levels of the proinflammatory cytokine IL-6 [276].

Cumulatively, these results indicate that activating CB2 receptors may decrease inflammation and avert neuronal death in the 6-OHDA model of PD. Investigations pertaining to the effects of cannabinoids on survival of isolated neuronal cells after 6-OHDA treatment revealed that the effects are mediated and governed by microglia [225]. Numerous CB receptor agonists, including 8-THC and 9-THC, decrease discharge of the proinflammatory cytokines tumor necrosis factor- $\alpha$ (TNF- $\alpha$ ) and interleukins by human monocytes [103]. Additionally,
WIN-55,212-2, cannabidiol and JWH-133 (CB2 receptor selective agonist), were all reported to decrease the ATP-induced rise in intracellular $\mathrm{Ca}^{2+}$ concentration in the N13 microglial cell line [277]. The effects of JWH-133 and WIN-55,212-2 were totally reversed by the selective CB2 antagonist, SR 144528 indicating a CB2 receptor dependent effect. However this antagonism was not observed in cannabidiol treated cells, indicating that CB2-independent mechanisms may also be favorable [277]. This CB2-independent mechanism involves the official pathway for the anti-inflammatory effects of most cannabinoid agonists [239]. Anti-inflammatory effects of cannabidiol are also associated with the regulation of microglial cell migration [104] and toxicity that stimulates production of pro-inflammatory mediators by these cells [274]. Cannabidiol interferes with transcription of NF-kB signaling and thereby controls the effectors genes contributing to inflammatory enzymes such as inducible NOS $[274,278]$. This NFKB inhibitory signaling mechanism may occur by decreasing p38 MAPK phosphorylation and 
hence avoiding its nuclear translocation to prompt expression of proinflammatory genes [278]. It has also been hypothesized that cannabidiol might bind peroxisome proliferator-activated receptor gamma [279,280], which antagonizes the action of NF- $\mathrm{KB}$ and thereby decreases the expression of pro-inflammatory enzymes, proinflammatory cytokines, and metalloproteases [281,280]. Although this proposed mechanism demands further study and confirmation, cannabidiol may elicit its antiinflammatory effects by stimulating nuclear receptors and modulating their downstream targets (Figure 2). All these studies suggest that use of CB2 agonists [82,103] may mitigate neuroinflammation by modulating the activities of microglial cell which have been implicated in the pathogenesis of PD $[41,82,282]$.

\section{Therapeutic role of cannabinoids in excitotoxicity in PD}

The theory of excitotoxicity has long been applied to PD. Studies have confirmed that parkin controls the stability and function of excitatory glutamatergic synapses. Postsynaptic expression of parkin inhibits excitatory synaptic transmission and results in a marked loss of excitatory synapses in hippocampal neurons. In contrast, a deficiency of endogenous parkin or expression of parkin mutants linked to PD strongly improves synaptic efficiency and activates glutamatergic synapses. This activation is related with increased susceptibility to synaptic excitotoxicity [283]. The resulting excess glutamatergic transmission could be a source of excitotoxicity in the substantia nigra. In addition, continuous stimulation of NMDA receptors increases intracellular calcium levels and produces uncontrolled shifts in sodium, potassium, and calcium concentrations that disrupt ionic homeostasis and lead to severe cell swelling and cell death in PD $[284,285]$. Recently scientific researchers also explored the role of WIN-55,212-2 in dopaminergic neuronal death induced by a proteasomal synthase inhibitor (PSI) as well as its modulatory function in cytoplasmic accumulation of parkin and $\alpha$-synuclein. WIN-55,212-2 was observed to protect PC12 cells from PSI-induced cytotoxicity by impeding PSI-induced poly-ADP ribose polymerase expression and activation of caspase- 3 . On the other hand WIN-55,212-2 was also found to decrease the cytoplasmic accumulation of parkin and $\alpha$-synuclein. However in contrast to earlier report [286], where CB1 receptor agonist was documented to inhibit NF- $\mathrm{kB}$ activity; WIN-55,212-2 in combination with PSI was observed to potentiate the nuclear translocation of NF- $\mathrm{kB}$ in PC12 cells. This data indicates that WIN-55,212-2 modulates apoptosis induced by proteasomal inhibition, partly by regulating NF- $\mathrm{KB}$ activity. Lately it was documented that WIN-55,212-2 requires the presence of histidine triad nucleotide-binding protein 1 (HINT1) protein to neutralize the toxic effects of NMDA receptor mediated
NO production and zinc release. This report hints towards HINT1 as a novel protein required for cannabinoid mediated protection against NMDA receptor-induced brain damage [287]. Apart from typical cannabinoid agonist and antagonists, FAAH inhibitors are also important to stimulate $\mathrm{CB} 1$ signaling mediated neuroprotection since, they are devoid of psychotropic effects associated with CB1 agonist [288]. In line with this reports, AM5206, a novel class of reversible FAAH inhibitor was investigated and demonstrated to provide neuroprotection in vitro and in vivo. In this study, AM5206 was found to protect pre and postsynaptic proteins in kainic acid induced excitotoxic damage to cultured hippocampal slices and rats [289]. This report supports the idea wherein ECBs provide protection against acute excitotoxicity [290]. In a related study, treatment with WIN-55,212-2 was found to inhibit TNF- $\alpha$-induced rise in $\alpha$-amino-3-hydroxy-5-methyl-4isoxazolepropionic acid (AMPA) receptors and excitotoxicity in hippocampal cultures [291].

The prominence of CB1 receptors has been established in circumstances of excitotoxicity, such as those in rats lesioned with the excitotoxin quinolinate in the striatum [292]. Reducing glutamate release is a prominent effect of cannabinoid agonists that might affirm their role as potential anti-excitotoxic compounds for use as PD therapeutics (Figure 1) [57,293,294]. This effect has been verified both in vitro, using neuronal cultures from spinal cord [295] or from various brain regions [296], and in vivo using rodent models to induce ischemia [297]. Activating presynaptically located CB1 receptors with a cannabinoid agonist on glutamatergic terminals of subthalamonigral neurons leads to decreased glutamate release. This inhibitory effect of cannabinoid agonists on glutamate release is reversed by the selective CB1 receptor antagonist SR-141716 [298]. As CB1 receptors are expressed on the synapses of two opposing (glutamatergic/excitatory and GABAergic/inhibitory) neuronal populations, hence the activation of one and/or another receptor population may possibly induce dissimilar effects [299]. Despite various reports, precise mechanism for CB1 mediated neuroprotection is unknown. Lately, it was demonstrated that only restricted population of $\mathrm{CB} 1$ receptors located on glutamatergic terminal are necessary to protect neurons against excitotoxicity [299]. In context with these findings recently it was found that cannabinoid receptor interacting protein (CRIP1a) alters the neuroprotective ability of WIN-55,212-2 in cortical neurons exposed to glutamate by acting as a cannabinoid antagonist rather than an agonist [300]. Some selective cannabinoids, such as anandamide and dexanabinol (HU-211), directly act on NMDA receptors [293]. The neuroprotective activity of dexanabinol originates from its ability to directly inhibit the glutamate system by antagonizing the NMDA receptor at a site close to, but 
different from that of glutamate, glycine, MK-801 and phencyclidine [293,301]. Depending on this antagonistic ability, HU-211 directly diminishes NMDA-mediated $\mathrm{Ca}^{2+}$ influx into neurons [302]. Although dexanabinol also offers neuroprotection [303] and reduces the levels of TNF- $\alpha$ [234], because of it is antioxidant properties. Anandamide directly acts with NMDA receptors in cortical, hippocampal and cerebellar slices and decreases the NMDA-mediated calcium response [304]. This effect is independent of its neuroprotective effects mediated by activation of cannabinoid receptors. As cannabinoids have a well-known ability to inhibit glutamate release from subthalamonigral neurons [305], CB1 receptor agonists may also be useful to improve tremors observed in PD [306]. However, a clinical study carried out to confirm the effects of cannabinoids on parkinsonian tremor did not reproduce this preclinical finding [307].

\section{Therapeutic role of cannabinoids in neurogenesis in PD}

Neurogenesis is the physiological process in which new neurons are generated and incorporated into the brain. Loss of neurite is one of the cardinal features of neuronal injury. Regulation of neurogenesis is stringently orchestrated by a number of different elements such as trophic factors, neurotransmitter systems and inflammatory cytokines. The establishment of new neurons and their connections is very essential for supporting normal neuronal function in neurodegenerative disorders where neurogenesis is impaired [308,309]. Neuroimmune networks and the brain ECB system have been closely associated to the process of adult neurogenesis $[308,310]$. For instance, genetic deletion of CB1 receptors leads to defective neurogenesis [311]. Also, they have been implicated in proliferation and neurogenesis of neural precursors in a model of excitotoxicity [312]. CB1 and CB2 receptors along with diacylglycerol lipase $\alpha$ have been identified in neural stem cells (NSC) where they govern and repair the proliferation of precursor cell in neurogenesis [313,314]. CB2 receptor has also been recognized as a physiological supervisor of proliferation in neural progenitor cells (NPC) [114]. In addition to $\mathrm{CB} 1$ and $\mathrm{CB} 2$ receptors, neurogenesis and expression of BDNF is also regulated at cellular level by ECB system. Endocannabinoids are observed to subdue neuroinflammatory processes contributing to the development of brain ageing as well as to the pathogenesis of neurodegenerative diseases [315]. Recently in animal models and postmortem studies of PD, adult neurogenesis was significantly affected, although the precise mechanisms and effects of these deviations are not yet fully understood [316]. Chronic neuroinflammation [317], mutant $\alpha$-synuclein and aging have been demonstrated to decrease neurogenesis in the various stages of PD [318-320]. These findings are predominantly exciting, as they increase the probability of a role for endocannabinoids in protecting degenerated neurons in PD. Few studies have shown that, stimulation of CB1 receptor increases levels of BDNF [321] a neurotrophin required for adult neurogenesis [322] that is decreased in the PD brain [323,324]. In a mutual way, BDNF was also observed to increase neuronal sensitivity to 2-AG and noladin ether in cultured cerebellar granule neuronal cells [325]. Additionally, stimulation of CB1 receptor-mediated neurogenesis also acts through antagonizing the antineurogenic effect of NO [276,326].

Lately, it has been suggested that the diacylglycerol lipase-CB2 pathway by controlling neurogenesis in subventricular zone might help to reverse the decline in neurogenesis that occurs during aging [327]. In line with this report, age-linked decrease in neurogenesis was partially reinstated by treatment with WIN-55,212-2 in male F-344 rats [276]. On another hand, pharmacological agonism at $\mathrm{CB} 2$ receptor and inhibition of FAAH can also stimulate neurogenesis in the adult mouse [328]. New studies have discovered that NPC express CB1 and CB2 receptors. While stimulation of downstream PI3K-AKT-mTOR complex 1 signalling pathway along with $\mathrm{CB} 2$ receptors by endocannabinoids and non-psychoactive cannabinoids controls the extension of the NPC pool in vitro and in vivo [114,329]. Stimulation of cannabinoid receptors also is documented to suppresses chronic inflammatory responses through the reduction of pro-inflammatory mediators [314]. In a very recent experiment, pharmacological antagonism of $\mathrm{CB} 1$ and/or CB2 receptors eliminated or reduced proliferation of NSC. Thus indicating a vital role for both CB1 and CB2 receptors in the proliferation of NSC via IL-1 signaling pathway, which may be of therapeutic interest in the developing field of brain repair [314]. Specific agonism of CB1 receptors by ACEA displayed neuronal differentiation and maturation of NSC. Although treatment with CB2-specific agonist; JWH133 was futile to achieve a similar profile [330]. In contrast to this study, CB2-specific agonist, AM1241 was observed to stimulate differentiation of NPCs to neuronal cells. Also, administration of AM1241 to GFAP/Gp120 Tg mice lead to escalation of in vivo neurogenesis in the hippocampus as confirmed by growth in neuroblast and neuronal cells. Furthermore, treatment with AM1241 diminished astrogliosis and gliogenesis in GFAP/Gp120 Tg mice [331]. In conclusion, targeting ECB system at specific and selective level in the future might help to replenish and sustain the neural functions in PD.

\section{Conclusion and future directions}

Numerous investigations have supported the observation that significant modulation of the cannabinoid signaling system occurs in PD. This conception has been reinforced by different electrophysiological, anatomical, and 
pharmacological findings. Therefore, pharmacological modulation of this this system with compounds that selectively target different elements of cannabinoid signaling may improve anomalies of motor behavior and provide neuroprotection. As cannabinoid-mediated functions do not control the cell activity directly coupled with their limited involvement in controlling brain functions, targeting the cannabinoid system may provide desired benefits in PD. Regardless of the experimental data, considerable number of issues need to be addressed, such as how, when, and where the ECBs function and how targeting ECB signaling could be a therapeutic advantage in PD. The important issues related to PD are motor disability and progressive nigral cell death. Despite existing therapies, no effective therapeutic intervention alleviates motor disabilities or provides neuroprotection. In contrast, substitute therapies for levodopa cause dyskinesia. Data in the past suggests that novel compounds with potent and specific activity for CB1, CB2, and TRPV1 receptors can be considered for treating PD. Compounds that selectively antagonize CB1 and perhaps TRPV1 receptors, may improve the motor disabilities such as bradykinesia and LID. The antioxidant mechanisms of certain cannabinoid compounds, which are independent of their cannabinoid receptor activity, also have a potential to be developed as a therapeutic PD. A second feature worthy of additional experimentation would be to elucidate the function and subsequent therapeutic potential of CB2 receptors in PD, as $\mathrm{CB} 2$ receptor agonists have curbed the inflammatory response incited by microglia in PD.

However it is recommended to develop antioxidant cannabinoids that lack CB1 receptor activity, as compounds with a CB1 interaction show deleterious effects on mitochondrial biogenesis and may exacerbate PD pathology [332]. Similarly, cannabinoids also have high abuse potential and cause dependence [333]. Therefore, drugs that modulate ECB levels by preventing their metabolism (FAAH and MAGL inhibitors) are therapeutically attractive targets, as they seem to have low or no abuse liability [333]. If these discoveries of cannabinoidmediated suppression of inflammation and alleviation of motor symptoms are translated from preclinical to clinical systems, then cannabinoids might seem to be encouraging therapeutic for PD. However, emerging contradictory results from animal models simulating PD demand development of new pharmacological tools, improved screening models, upgraded technologies, and specific ligands for evaluating the therapeutic potential of cannabinoids in PD. Most studies investigating the therapeutic potential of cannabinoids in PD have been conducted in animal models, and an insufficient number of clinical trials have been carried out. Therefore, the therapeutic benefits demonstrated in animal models need more clinical evidence. Another challenge in PD is to develop a multifunctional or broad-spectrum cannabinoid that could decrease existing motor abnormalities, oxidative stress, and microglial activation seen in PD. To conclude, development of safe, effective cannabis-based medicines targeting different mechanisms may have a significant impact in PD therapy.

\section{Abbreviations}

2-AG: 2-arachidonoyl glycerol; 6-OHDA: 6-hydroxy dopamine; ALS: Amyotrophic lateral sclerosis; AD: Alzheimer's disease; AMT: Anandamide membrane transporter; AIM: Abnormal involuntary movements; AMPA: a-amino-3-hydroxy-5-methyl-4isoxazolepropionic acid; BDNF: Brain derived neurotrophic factor; COX2: Cyclooxygenase 2; CaMKII: Calcium/calmodulin-dependent protein kinase II; DRG: Dorsal root ganglion; ECB: Endocannabinoid; FAAH: Fatty acid amide hydrolase; GABA: Gamma-aminobutyric acid; GPe: External segment of Globus pallidus; GPi: Internal segment of Globus pallidus; HD: Huntington's disease; iNOS: Inducible nitric oxide synthase; LID: Levodopa-induced dyskinesia; LTD: Long-term depression; LTP: Long-term potentiation; MAGL: Monoacylglycerol lipase; MSNs: Medium spiny neurons; MS: Multiple sclerosis; MPTP: 1-methyl-4phenyl-1,2,3,6-tetrahydropyridine; MAPK: Mitogen activated protein kinase; NO: Nitric oxide; NAPE-PLD: N-acyl phosphatidylethanolamine-specific phospholipase D; Noladin ether: 2-arachidonoyl glyceryl ether; Nrf-2: Nuclear factor erythroid 2-related factor 2; NPC: Neural progenitor cells; NSC: Neural stem cells; OEA: Oleoylethanolamide; O-arachidonoyl ethanolamine: Virodhamine; PD: Parkinson's disease; PSI: Proteasomal synthase inhibitor; ROS: Reactive oxygen species; RGS4: Regulator of G-protein Signaling 4; SNpc: Substantia nigra pars compacta; SNpr: Substantia nigra pars reticulata; STN: Subthalamic nucleus; TNF-a: Tumor necrosis factor-a.

\section{Competing interests}

The authors declare that they have no competing interests.

\section{Authors' contributions}

SM was involved in reviewing the literature and constructing the manuscript along with diagrams. DC was involved in intellectual input and editorial suggestions. All authors read and approved the final manuscript.

\section{Acknowledgement}

This work was supported by a National Research Foundation Grant (2014R1A2A2A04007791) funded by Korean Government.

Received: 14 January 2015 Accepted: 23 March 2015

Published online: 08 April 2015

\section{References}

1. Connolly BS, Lang AE. Pharmacological treatment of Parkinson disease: a review. JAMA. 2014;311:1670-83.

2. Skibinski G, Finkbeiner S. Drug discovery in Parkinson's disease-Update and developments in the use of cellular models. Int J High Throughput Screen. 2011;2011:15-25

3. Thomas B, Beal MF. Parkinson's disease. Hum Mol Genet. 2007; 16 Spec No. 2:R183-194.

4. Thomas B. Parkinson's disease: from molecular pathways in disease to therapeutic approaches. Antioxid Redox Signal. 2009;11:2077-82.

5. Schapira AH, Olanow CW, Greenamyre JT, Bezard E. Slowing of neurodegeneration in Parkinson's disease and Huntington's disease: future therapeutic perspectives. Lancet. 2014:384:545-55.

6. Davie CA. A review of Parkinson's disease. Br Med Bull. 2008;86:109-27.

7. Utsumi H, Okuma Y, Kano O, Suzuki Y, lijima M, Tomimitsu H, et al. Evaluation of the efficacy of pramipexole for treating levodopa-induced dyskinesia in patients with Parkinson's disease. Intern Med. 2013;52:325-32.

8. Fernandez-Ruiz J, Moreno-Martet M, Rodriguez-Cueto C, Palomo-Garo C, Gomez-Canas M, Valdeolivas S, et al. Prospects for cannabinoid therapies in basal ganglia disorders. Br J Pharmacol. 2011;163:1365-78.

9. Hashimotodani Y, Ohno-Shosaku T, Kano M. Presynaptic monoacylglycerol lipase activity determines basal endocannabinoid tone and terminates retrograde endocannabinoid signaling in the hippocampus. J Neurosci. 2007;27:1211-9. 
10. Hegyi Z, Hollo K, Kis G, Mackie K, Antal M. Differential distribution of diacylglycerol lipase-alpha and $\mathrm{N}$-acylphosphatidylethanolamine-specific phospholipase $\mathrm{d}$ immunoreactivity in the superficial spinal dorsal horn of rats. Glia. 2012:60:1316-29.

11. Ivanov I, Borchert P, Hinz B. A simple method for simultaneous determination of $\mathrm{N}$-arachidonoylethanolamine, $\mathrm{N}$-oleoylethanolamine, $\mathrm{N}$-palmitoylethanolamine and 2-arachidonoylglycerol in human cells. Anal Bioanal Chem. 2014:407:1781-7.

12. Snider NT, Walker VJ, Hollenberg PF. Oxidation of the endogenous cannabinoid arachidonoyl ethanolamide by the cytochrome P450 monooxygenases: physiological and pharmacological implications Pharmacol Rev. 2010;62:136-54

13. Pertwee RG, Howlett AC, Abood ME, Alexander SP, Di Marzo V, Elphick MR, et al. International Union of Basic and Clinical Pharmacology. LXXIX. Cannabinoid receptors and their ligands: beyond $\mathrm{CB}(1)$ and $\mathrm{CB}(2)$. Pharmacol Rev. 2010;62:588-631.

14. Buczynski MW, Parsons LH. Quantification of brain endocannabinoid levels: methods, interpretations and pitfalls. Br J Pharmacol. 2010;160:423-42.

15. Felder CC, Nielsen A, Briley EM, Palkovits M, Priller J, Axelrod J, et al. Isolation and measurement of the endogenous cannabinoid receptor agonist, anandamide, in brain and peripheral tissues of human and rat. FEBS Lett. 1996:393:231-5

16. Bisogno T, Berrendero F, Ambrosino G, Cebeira M, Ramos JA, Fernandez-Ruiz $J$ J, et al. Brain regional distribution of endocannabinoids: implications for their biosynthesis and biological function. Biochem Biophys Res Commun. 1999;256:377-80

17. Mechoulam R, Ben-Shabat S, Hanus L, Ligumsky M, Kaminski NE, Schatz AR, et al. Identification of an endogenous 2-monoglyceride, present in canine gut, that binds to cannabinoid receptors. Biochem Pharmacol. 1995:50:83-90.

18. Gonsiorek W, Lunn C, Fan X, Narula S, Lundell D, Hipkin RW. Endocannabinoid 2-arachidonyl glycerol is a full agonist through human type 2 cannabinoid receptor: antagonism by anandamide. Mol Pharmacol. 2000;57:1045-50.

19. Sugiura T, Kondo S, Kishimoto S, Miyashita T, Nakane S, Kodaka T, et al. Evidence that 2-arachidonoylglycerol but not N-palmitoylethanolamine or anandamide is the physiological ligand for the cannabinoid CB2 receptor. Comparison of the agonistic activities of various cannabinoid receptor ligands in HL-60 cells. J Biol Chem. 2000;275:605-12.

20. Herkenham M, Lynn AB, Johnson MR, Melvin LS, de Costa BR, Rice KC. Characterization and localization of cannabinoid receptors in rat brain: a quantitative in vitro autoradiographic study. J Neurosci. 1991;11:563-83.

21. Di Marzo V, Hill MP, Bisogno T, Crossman AR, Brotchie JM. Enhanced levels of endogenous cannabinoids in the globus pallidus are associated with a reduction in movement in an animal model of Parkinson's disease. FASEB J. 2000;14:1432-8.

22. Di Marzo V, Berrendero F, Bisogno T, Gonzalez S, Cavaliere P, Romero J, et al. Enhancement of anandamide formation in the limbic forebrain and reduction of endocannabinoid contents in the striatum of delta9tetrahydrocannabinol-tolerant rats. J Neurochem. 2000;74:1627-35.

23. Giuffrida A, Parsons LH, Kerr TM, Rodriguez de Fonseca F, Navarro M, Piomelli D. Dopamine activation of endogenous cannabinoid signaling in dorsal striatum. Nat Neurosci. 1999:2:358-63.

24. Saito A, Ballinger MD, Pletnikov MV, Wong DF, Kamiya A. Endocannabinoid system: potential novel targets for treatment of schizophrenia. Neurobiol Dis. 2013;53:10-7.

25. Harkany T, Guzman M, Galve-Roperh I, Berghuis P, Devi LA, Mackie K. The emerging functions of endocannabinoid signaling during CNS development. Trends Pharmacol Sci. 2007;28:83-92.

26. Bisogno T, Howell F, Williams G, Minassi A, Cascio MG, Ligresti A, et al. Cloning of the first sn1-DAG lipases points to the spatial and temporal regulation of endocannabinoid signaling in the brain. J Cell Biol. 2003;163:463-8.

27. Murataeva N, Straiker A, Mackie K. Parsing the players: 2-arachidonoylglycerol synthesis and degradation in the CNS. Br J Pharmacol. 2014;171:1379-91.

28. Di Marzo V, Fontana A, Cadas H, Schinelli S, Cimino G, Schwartz JC, et al. Formation and inactivation of endogenous cannabinoid anandamide in central neurons. Nature. 1994;372:686-91.

29. Maccarrone M, van der Stelt M, Rossi A, Veldink GA, Vliegenthart JF, Agro AF. Anandamide hydrolysis by human cells in culture and brain. J Biol Chem. 1998:273:32332-9.
30. Castillo PE, Younts TJ, Chavez AE, Hashimotodani Y. Endocannabinoid signaling and synaptic function. Neuron. 2012;76:70-81.

31. Egertova M, Giang DK, Cravatt BF, Elphick MR. A new perspective on cannabinoid signalling: complementary localization of fatty acid amide hydrolase and the CB1 receptor in rat brain. Proc Biol Sci. 1998;265:2081-5.

32. Gulyas Al, Cravatt BF, Bracey MH, Dinh TP, Piomelli D, Boscia F, et al. Segregation of two endocannabinoid-hydrolyzing enzymes into pre- and postsynaptic compartments in the rat hippocampus, cerebellum and amygdala. Eur J Neurosci. 2004;20:441-58.

33. Alexander S. Endocannabinoid-Metabolising Enzymes. Br J Pharmacol. 2009;158:S220-1.

34. Di Marzo V, Bisogno T, Sugiura T, Melck D, De Petrocellis $L$. The novel endogenous cannabinoid 2-arachidonoylglycerol is inactivated by neuronal- and basophil-like cells: connections with anandamide. Biochem J. 1998;331(Pt 1):15-9.

35. Goparaju SK, Ueda N, Yamaguchi H, Yamamoto S. Anandamide amidohydrolase reacting with 2-arachidonoylglycerol, another cannabinoid receptor ligand. FEBS Lett. 1998;422:69-73.

36. Dinh TP, Carpenter D, Leslie FM, Freund TF, Katona I, Sensi SL, et al. Brain monoglyceride lipase participating in endocannabinoid inactivation. Proc Natl Acad Sci U S A. 2002;99:10819-24.

37. Tanimura A, Uchigashima M, Yamazaki M, Uesaka N, Mikuni T, Abe M, et al Synapse type-independent degradation of the endocannabinoid 2-arachidonoylglycerol after retrograde synaptic suppression. Proc Natl Acad Sci U S A. 2012;109:12195-200

38. Bektas M, Payne SG, Liu H, Goparaju S, Milstien S, Spiegel S. A novel acylglycerol kinase that produces lysophosphatidic acid modulates cross talk with EGFR in prostate cancer cells. J Cell Biol. 2005;169:801-11.

39. Kozak KR, Marnett LJ. Oxidative metabolism of endocannabinoids. Prostaglandins Leukot Essent Fatty Acids. 2002;66:211-20.

40. Marzo VD. Cannabinoids. Georgetown, Texas, USA: Plenum Publishers; 2004.

41. Sagredo O, Garcia-Arencibia M, de Lago E, Finetti S, Decio A, Fernandez-Ruiz J. Cannabinoids and neuroprotection in basal ganglia disorders. Mol Neurobiol. 2007;36:82-91.

42. Price DA, Martinez AA, Seillier A, Koek W, Acosta Y, Fernandez E, et al. WIN55,212-2, a cannabinoid receptor agonist, protects against nigrostriatal cell loss in the 1-methyl-4-phenyl-1,2,3,6-tetrahydropyridine mouse model of Parkinson's disease. Eur J Neurosci. 2009:29:2177-86.

43. Groenewegen HJ. The basal ganglia and motor control. Neural Plast. 2003;10:107-20

44. Fernandez-Ruiz J, Sagredo O, Pazos MR, Garcia C, Pertwee R, Mechoulam R, et al. Cannabidiol for neurodegenerative disorders: important new clinical applications for this phytocannabinoid? Br J Clin Pharmacol. 2013;75:323-33.

45. Matsuda LA, Lolait SJ, Brownstein MJ, Young AC, Bonner TI. Structure of a cannabinoid receptor and functional expression of the cloned CDNA. Nature. 1990;346:561-4.

46. Munro S, Thomas KL, Abu-Shaar M. Molecular characterization of a peripheral receptor for cannabinoids. Nature. 1993;365:61-5.

47. Howlett AC, Barth F, Bonner TI, Cabral G, Casellas P, Devane WA, et al. International Union of Pharmacology. XXVII. Classification of cannabinoid receptors. Pharmacol Rev. 2002;54:161-202.

48. Mackie K, Lai Y, Westenbroek R, Mitchell R. Cannabinoids activate an inwardly rectifying potassium conductance and inhibit Q-type calcium currents in AtT20 cells transfected with rat brain cannabinoid receptor. J Neurosci. 1995;15:6552-61.

49. Twitchell W, Brown S, Mackie K. Cannabinoids inhibit N- and P/Q-type calcium channels in cultured rat hippocampal neurons. J Neurophysiol. 1997:78:43-50

50. Turu G, Hunyady L. Signal transduction of the CB1 cannabinoid receptor J Mol Endocrinol. 2010:44:75-85.

51. Derkinderen P, Toutant M, Burgaya F, Le Bert M, Siciliano JC, de Franciscis V, et al. Regulation of a neuronal form of focal adhesion kinase by anandamide. Science. 1996;273:1719-22

52. Gomez Del Pulgar T, De Ceballos ML, Guzman M, Velasco G. Cannabinoids protect astrocytes from ceramide-induced apoptosis through the phosphatidylinositol 3-kinase/protein kinase B pathway. J Biol Chem. 2002;277:36527-33

53. Sanchez C, Galve-Roperh I, Rueda D, Guzman M. Involvement of sphingomyelin hydrolysis and the mitogen-activated protein kinase cascade in the Delta9-tetrahydrocannabinol-induced stimulation of glucose metabolism in primary astrocytes. Mol Pharmacol. 1998;54:834-43. 
54. Waksman Y, Olson JM, Carlisle SJ, Cabral GA. The central cannabinoid receptor (CB1) mediates inhibition of nitric oxide production by rat microglial cells. J Pharmacol Exp Ther. 1999;288:1357-66.

55. Bosier B, Muccioli GG, Hermans E, Lambert DM. Functionally selective cannabinoid receptor signalling: therapeutic implications and opportunities. Biochem Pharmacol. 2010;80:1-12.

56. Benard G, Massa F, Puente N, Lourenco J, Bellocchio L, Soria-Gomez E, et al. Mitochondrial $\mathrm{CB}(1)$ receptors regulate neuronal energy metabolism. Nat Neurosci. 2012;15:558-64

57. Romero J, Lastres-Becker I, de Miguel R, Berrendero F, Ramos JA, Fernandez-Ruiz J. The endogenous cannabinoid system and the basal ganglia. biochemical, pharmacological, and therapeutic aspects. Pharmacol Ther. 2002;95:137-52.

58. Martin AB, Fernandez-Espejo E, Ferrer B, Gorriti MA, Bilbao A, Navarro M, et al. Expression and function of CB1 receptor in the rat striatum: localization and effects on D1 and D2 dopamine receptor-mediated motor behaviors. Neuropsychopharmacology. 2008;33:1667-79.

59. Calabresi P, Picconi B, Tozzi A, Ghiglieri V, Di Filippo M. Direct and indirect pathways of basal ganglia: a critical reappraisal. Nat Neurosci. 2014;17:1022-30.

60. Munoz-Arenas G, Paz-Bermudez F, Baez-Cordero A, Caballero-Floran R, Gonzalez-Hernandez B, Floran B, et al. Cannabinoid CB1 receptors activation and coactivation with D2 receptors modulate GABAergic neurotransmission in the globus pallidus and increase motor asymmetry. Synapse. 2014:69:103-14

61. Sierra S, Luquin N, Rico AJ, Gomez-Bautista V, Roda E, Dopeso-Reyes IG et al. Detection of cannabinoid receptors CB1 and CB2 within basal ganglia output neurons in macaques: changes following experimental parkinsonism. Brain Struct Funct. 2014. Epub ahead of print.

62. Mailleux P, Vanderhaeghen JJ. Distribution of neuronal cannabinoid receptor in the adult rat brain: a comparative receptor binding radioautography and in situ hybridization histochemistry. Neuroscience. 1992;48:655-68.

63. Herkenham M, Lynn AB, de Costa BR, Richfield EK. Neuronal localization of cannabinoid receptors in the basal ganglia of the rat. Brain Res. 1991:547:267-74

64. Chaves-Kirsten GP, Mazucanti CH, Real CC, Souza BM, Britto LR, Torrao AS Temporal changes of $C B 1$ cannabinoid receptor in the basal ganglia as a possible structure-specific plasticity process in 6-OHDA lesioned rats. PLoS One. 2013;8:e76874.

65. Kofalvi A, Rodrigues RJ, Ledent C, Mackie K, Vizi ES, Cunha RA, et al. Involvement of cannabinoid receptors in the regulation of neurotransmitter release in the rodent striatum: a combined immunochemical and pharmacological analysis. J Neurosci. 2005;25:2874-84.

66. Hohmann AG, Herkenham M. Localization of cannabinoid CB(1) receptor mRNA in neuronal subpopulations of rat striatum: a double-label in situ hybridization study. Synapse. 2000;37:71-80

67. Chiu CQ, Puente N, Grandes P, Castillo PE. Dopaminergic modulation of endocannabinoid-mediated plasticity at GABAergic synapses in the prefrontal cortex. J Neurosci. 2010;30:7236-48.

68. Coria SM, Roura-Martinez D, Ucha M, Assis MA, Miguens M, Garcia-Lecumberri $C$, et al. Strain differences in the expression of endocannabinoid genes and in cannabinoid receptor binding in the brain of Lewis and Fischer 344 rats. Prog Neuropsychopharmacol Biol Psychiatry. 2014;53:15-22.

69. Van Waes V, Beverley JA, Siman H, Tseng KY, Steiner H. CB1 Cannabinoid Receptor Expression in the Striatum: Association with Corticostriatal Circuits and Developmental Regulation. Front Pharmacol. 2012;3:21.

70. Ferre S, Goldberg SR, Lluis C, Franco R. Looking for the role of cannabinoid receptor heteromers in striatal function. Neuropharmacology. 2009;56 Suppl 1:226-34.

71. Hill MN, McLaughlin RJ, Pan B, Fitzgerald ML, Roberts CJ, Lee TT, et al. Recruitment of prefrontal cortical endocannabinoid signaling by glucocorticoids contributes to termination of the stress response. J Neurosci. 2011;31:10506-15.

72. Allen KL, Waldvogel HJ, Glass M, Faull RL. Cannabinoid (CB(1)), GABA(A) and $G A B A(B)$ receptor subunit changes in the globus pallidus in Huntington's disease. J Chem Neuroanat. 2009;37:266-81.

73. Dowie MJ, Bradshaw HB, Howard ML, Nicholson LF, Faull RL, Hannan AJ, et al. Altered CB1 receptor and endocannabinoid levels precede motor symptom onset in a transgenic mouse model of Huntington's disease. Neuroscience. 2009:163:456-65.
74. Walsh S, Mnich K, Mackie K, Gorman AM, Finn DP, Dowd E. Loss of cannabinoid CB1 receptor expression in the 6-hydroxydopamine-induced nigrostriatal terminal lesion model of Parkinson's disease in the rat. Brain Res Bull. 2010:81:543-8.

75. Spiga S, Lintas A, Migliore M, Diana M. Altered architecture and functional consequences of the mesolimbic dopamine system in cannabis dependence. Addict Biol. 2010;15:266-76.

76. Matyas F, Urban GM, Watanabe M, Mackie K, Zimmer A, Freund TF, et al. Identification of the sites of 2-arachidonoylglycerol synthesis and action imply retrograde endocannabinoid signaling at both GABAergic and glutamatergic synapses in the ventral tegmental area. Neuropharmacology. 2008;54:95-107.

77. Dasilva M, Grieve KL, Cudeiro J, Rivadulla C. Anandamide activation of CB1 receptors increases spontaneous bursting and oscillatory activity in the thalamus. Neuroscience. 2014:265:72-82.

78. Ledent C, Valverde O, Cossu G, Petitet F, Aubert JF, Beslot F, et al. Unresponsiveness to cannabinoids and reduced addictive effects of opiates in CB1 receptor knockout mice. Science. 1999;283:401-4.

79. Zimmer A, Zimmer AM, Hohmann AG, Herkenham M, Bonner TI. Increased mortality, hypoactivity, and hypoalgesia in cannabinoid CB1 receptor knockout mice. Proc Natl Acad Sci U S A. 1999:96:5780-5.

80. Polissidis A, Galanopoulos A, Naxakis G, Papahatjis D, Papadopoulou-Daifoti Z, Antoniou K. The cannabinoid CB1 receptor biphasically modulates motor activity and regulates dopamine and glutamate release region dependently. Int J Neuropsychopharmacol. 2013;16:393-403.

81. Pazos MR, Nunez E, Benito C, Tolon RM, Romero J. Functional neuroanatomy of the endocannabinoid system. Pharmacol Biochem Behav. 2005;81:239-47.

82. Stella N. Cannabinoid and cannabinoid-like receptors in microglia, astrocytes, and astrocytomas. Glia. 2010;58:1017-30.

83. Metna-Laurent M, Marsicano G. Rising stars: Modulation of brain functions by astroglial type-1 cannabinoid receptors. Glia. 2014;63:353-64.

84. Rodriguez JJ, Mackie K, Pickel VM. Ultrastructural localization of the CB1 cannabinoid receptor in mu-opioid receptor patches of the rat Caudate putamen nucleus. J Neurosci. 2001;21:823-33.

85. Katona I, Sperlagh B, Sik A, Kafalvi A, Vizi ES, Mackie K, et al. Presynaptically located CB1 cannabinoid receptors regulate GABA release from axon terminals of specific hippocampal interneurons. J Neurosci. 1999:19:4544-58.

86. Tsou K, Brown S, Sanudo-Pena MC, Mackie K, Walker JM. Immunohistochemical distribution of cannabinoid CB1 receptors in the rat central nervous system. Neuroscience. 1998;83:393-411.

87. Guzman M. Cannabinoids: potential anticancer agents. Nat Rev Cancer 2003:3:745-55.

88. Navarrete M, Araque A. Endocannabinoids mediate neuron-astrocyte communication. Neuron. 2008:57:883-93.

89. Carrier EJ, Kearn CS, Barkmeier AJ, Breese NM, Yang W, Nithipatikom K, et al. Cultured rat microglial cells synthesize the endocannabinoid 2 arachidonylglycerol, which increases proliferation via a CB2 receptor-dependent mechanism. Mol Pharmacol. 2004;65:999-1007.

90. More SV, Kumar H, Kim IS, Song SY, Choi DK. Cellular and molecular mediators of neuroinflammation in the pathogenesis of Parkinson's disease. Mediators Inflamm. 2013;2013:952375.

91. Beltramo M, Bernardini N, Bertorelli R, Campanella M, Nicolussi E, Fredduzzi $\mathrm{S}$, et al. CB2 receptor-mediated antihyperalgesia: possible direct involvement of neural mechanisms. Eur J Neurosci. 2006;23:1530-8.

92. Hsieh GC, Pai M, Chandran P, Hooker BA, Zhu CZ, Salyers AK, et al. Central and peripheral sites of action for $\mathrm{CB}(2)$ receptor mediated analgesic activity in chronic inflammatory and neuropathic pain models in rats. $\mathrm{Br} \mathrm{J}$ Pharmacol. 2011;162:428-40.

93. Ross RA, Coutts AA, McFarlane SM, Anavi-Goffer S, Irving AJ, Pertwee RG, et al. Actions of cannabinoid receptor ligands on rat cultured sensory neurones: implications for antinociception. Neuropharmacology. 2001;40:221-32.

94. Sokal DM, Elmes SJ, Kendall DA, Chapman V. Intraplantar injection of anandamide inhibits mechanically-evoked responses of spinal neurones via activation of CB2 receptors in anaesthetised rats. Neuropharmacology. 2003;45:404-11.

95. Skaper SD, Buriani A, Dal Toso R, Petrelli L, Romanello S, Facci L, et al. The ALIAmide palmitoylethanolamide and cannabinoids, but not anandamide, are protective in a delayed postglutamate paradigm of excitotoxic death in cerebellar granule neurons. Proc Natl Acad Sci U S A. 1996;93:3984-9. 
96. Rodriguez-Cueto C, Benito C, Fernandez-Ruiz J, Romero J, Hernandez-Galvez $\mathrm{M}$, Gomez-Ruiz M. Changes in $\mathrm{CB}(1)$ and $\mathrm{CB}(2)$ receptors in the post-mortem cerebellum of humans affected by spinocerebellar ataxias. Br J Pharmacol. 2014;171:1472-89.

97. Graham ES, Angel CE, Schwarcz LE, Dunbar PR, Glass M. Detailed characterisation of $\mathrm{CB} 2$ receptor protein expression in peripheral blood immune cells from healthy human volunteers using flow cytometry. Int J Immunopathol Pharmacol. 2010:23:25-34.

98. Stella N. Endocannabinoid signaling in microglial cells. Neuropharmacology. 2009:56 Suppl 1:244-53.

99. Merighi S, Gessi S, Varani K, Simioni C, Fazzi D, Mirandola P, et al. Cannabinoid $\mathrm{CB}(2)$ receptors modulate ERK-1/2 kinase signalling and $\mathrm{NO}$ release in microglial cells stimulated with bacterial lipopolysaccharide. $\mathrm{Br}$ J Pharmacol. 2012;165:1773-88.

100. Facchinetti F, Del Giudice E, Furegato S, Passarotto M, Leon A. Cannabinoids ablate release of TNFalpha in rat microglial cells stimulated with lypopolysaccharide. Glia. 2003;41:161-8.

101. Ashton JC, Friberg D, Darlington CL, Smith PF. Expression of the cannabinoid CB2 receptor in the rat cerebellum: an immunohistochemical study. Neurosci Lett. 2006;396:113-6.

102. Brusco A, Tagliaferro P, Saez T, Onaivi ES. Postsynaptic localization of CB2 cannabinoid receptors in the rat hippocampus. Synapse. 2008;62:944-9.

103. Klegeris A, Bissonnette CJ, McGeer PL. Reduction of human monocytic cell neurotoxicity and cytokine secretion by ligands of the cannabinoid-type CB2 receptor. Br J Pharmacol. 2003;139:775-86.

104. Walter L, Franklin A, Witting A, Wade C, Xie Y, Kunos G, et al. Nonpsychotropic cannabinoid receptors regulate microglial cell migration. J Neurosci. 2003;23:1398-405.

105. Benito C, Nunez E, Tolon RM, Carrier EJ, Rabano A, Hillard CJ, et al. Cannabinoid CB2 receptors and fatty acid amide hydrolase are selectively overexpressed in neuritic plaque-associated glia in Alzheimer's disease brains. J Neurosci. 2003:23:11136-41.

106. Nunez E, Benito C, Pazos MR, Barbachano A, Fajardo O, Gonzalez S, et al. Cannabinoid CB2 receptors are expressed by perivascular microglial cells in the human brain: an immunohistochemical study. Synapse. 2004;53:208-13.

107. Onaivi ES. Commentary: Functional Neuronal CB2 Cannabinoid Receptors in the CNS. Curr Neuropharmacol. 2011;9:205-8.

108. Morgan NH, Stanford IM, Woodhall GL. Functional CB2 type cannabinoid receptors at CNS synapses. Neuropharmacology. 2009;57:356-68.

109. Brusco A, Tagliaferro PA, Saez T, Onaivi ES. Ultrastructural localization of neuronal brain CB2 cannabinoid receptors. Ann N Y Acad Sci. 2008;1139:450-7.

110. den Boon FS, Chameau P, Schaafsma-Zhao Q, van Aken W, Bari M, Oddi S, et al. Excitability of prefrontal cortical pyramidal neurons is modulated by activation of intracellular type-2 cannabinoid receptors. Proc Natl Acad Sci U S A. 2012;109:3534-9.

111. Lanciego JL, Barroso-Chinea P, Rico AJ, Conte-Perales L, Callen L, Roda E, et al. Expression of the mRNA coding the cannabinoid receptor 2 in the pallidal complex of Macaca fascicularis. J Psychopharmacol. 2011;25:97-104.

112. Suarez J, Llorente R, Romero-Zerbo SY, Mateos B, Bermudez-Silva FJ, de Fonseca FR, et al. Early maternal deprivation induces gender-dependent changes on the expression of hippocampal $\mathrm{CB}(1)$ and $\mathrm{CB}(2)$ cannabinoid receptors of neonatal rats. Hippocampus. 2009;19:623-32

113. Ternianov A, Perez-Ortiz JM, Solesio ME, Garcia-Gutierrez MS, Ortega-Alvaro A, Navarrete F, et al. Overexpression of CB2 cannabinoid receptors results in neuroprotection against behavioral and neurochemical alterations induced by intracaudate administration of 6-hydroxydopamine. Neurobiol Aging. 2012:33:421. e421-416.

114. Palazuelos J, Aguado T, Egia A, Mechoulam R, Guzman M, Galve-Roperh I. Non-psychoactive CB2 cannabinoid agonists stimulate neural progenitor proliferation. FASEB J. 2006;20:2405-7

115. Sagredo O, Gonzalez S, Aroyo I, Pazos MR, Benito C, Lastres-Becker I, et al. Cannabinoid CB2 receptor agonists protect the striatum against malonate toxicity: relevance for Huntington's disease. Glia. 2009;57:1154-67.

116. Dhopeshwarkar A, Mackie K. CB2 Cannabinoid receptors as a therapeutic target-what does the future hold? Mol Pharmacol. 2014;86:430-7.

117. Mezey E, Toth ZE, Cortright DN, Arzubi MK, Krause JE, Elde R, et al, Distribution of mRNA for vanilloid receptor subtype 1 (VR1), and VR1-like immunoreactivity, in the central nervous system of the rat and human Proc Natl Acad Sci U S A. 2000;97:3655-60.
118. Cristino L, de Petrocellis L, Pryce G, Baker D, Guglielmotti V, Di Marzo V. Immunohistochemical localization of cannabinoid type 1 and vanilloid transient receptor potential vanilloid type 1 receptors in the mouse brain. Neuroscience. 2006;139:1405-15.

119. Cavanaugh DJ, Chesler AT, Jackson AC, Sigal YM, Yamanaka H, Grant R, et al. Trpv1 reporter mice reveal highly restricted brain distribution and functional expression in arteriolar smooth muscle cells. J Neurosci. 2011;31:5067-77.

120. Micale V, Cristino L, Tamburella A, Petrosino S, Leggio GM, Drago F, et al. Anxiolytic effects in mice of a dual blocker of fatty acid amide hydrolase and transient receptor potential vanilloid type-1 channels. Neuropsychopharmacology. 2009;34:593-606.

121. Di Marzo V, Lastres-Becker I, Bisogno T, De Petrocellis L, Milone A, Davis JB, et al. Hypolocomotor effects in rats of capsaicin and two long chain capsaicin homologues. Eur J Pharmacol. 2001;420:123-31.

122. de Lago E, de Miguel R, Lastres-Becker I, Ramos JA, Fernandez-Ruiz J. Involvement of vanilloid-like receptors in the effects of anandamide on motor behavior and nigrostriatal dopaminergic activity: in vivo and in vitro evidence. Brain Res. 2004;1007:152-9.

123. Brown AJ. Novel cannabinoid receptors. Br J Pharmacol. 2007:152:567-75.

124. Ryberg E, Larsson N, Sjogren S, Hjorth S, Hermansson NO, Leonova J, et al. The orphan receptor GPR55 is a novel cannabinoid receptor. $\mathrm{Br} J$ Pharmacol. 2007;152:1092-101.

125. Sharir H, Abood ME. Pharmacological characterization of GPR55, a putative cannabinoid receptor. Pharmacol Ther. 2010;126:301-13.

126. Sawzdargo M, Nguyen $T$, Lee DK, Lynch KR, Cheng $\mathrm{R}$, Heng $\mathrm{HH}$, et al. Identification and cloning of three novel human $\mathrm{G}$ protein-coupled receptor genes GPR52, PsiGPR53 and GPR55: GPR55 is extensively expressed in human brain. Brain Res Mol Brain Res. 1999:64:193-8.

127. Oka S, Nakajima K, Yamashita A, Kishimoto S, Sugiura T. Identification of GPR55 as a lysophosphatidylinositol receptor. Biochem Biophys Res Commun. 2007;362:928-34

128. Lauckner JE, Jensen JB, Chen HY, Lu HC, Hille B, Mackie K. GPR55 is a cannabinoid receptor that increases intracellular calcium and inhibits $M$ current. Proc Natl Acad Sci U S A. 2008;105:2699-704.

129. Lastres-Becker I, Cebeira M, de Ceballos ML, Zeng BY, Jenner P, Ramos JA, et al. Increased cannabinoid CB1 receptor binding and activation of GTP-binding proteins in the basal ganglia of patients with Parkinson's syndrome and of MPTP-treated marmosets. Eur J Neurosci. 2001;14:1827-32.

130. van der Stelt M, Fox SH, Hill M, Crossman AR, Petrosino S, Di Marzo V, et al. A role for endocannabinoids in the generation of parkinsonism and levodopa-induced dyskinesia in MPTP-lesioned non-human primate models of Parkinson's disease. FASEB J. 2005;19:1140-2.

131. Meschler JP, Howlett AC, Madras BK. Cannabinoid receptor agonist and antagonist effects on motor function in normal and 1-methyl-4-phenyl1,2,5,6-tetrahydropyridine (MPTP)-treated non-human primates. Psychopharmacology (Berl). 2001;156:79-85.

132. Centonze D, Finazzi-Agro A, Bernardi G, Maccarrone M. The endocannabinoid system in targeting inflammatory neurodegenerative diseases. Trends Pharmacol Sci. 2007;28:180-7.

133. Van Laere K, Casteels C, Lunskens S, Goffin K, Grachev ID, Bormans G, et al. Regional changes in type 1 cannabinoid receptor availability in Parkinson's disease in vivo. Neurobiol Aging. 2012;33:620. e621-628.

134. Prescott WR, Gold LH, Martin BR. Evidence for separate neuronal mechanisms for the discriminative stimulus and catalepsy induced by delta 9-THC in the rat. Psychopharmacology (Berl). 1992;107:117-24.

135. Crawley JN, Corwin RL, Robinson JK, Felder CC, Devane WA, Axelrod J. Anandamide, an endogenous ligand of the cannabinoid receptor, induces hypomotility and hypothermia in vivo in rodents. Pharmacol Biochem Behav. 1993;46:967-72.

136. Anderson LA, Anderson JJ, Chase TN, Walters JR. The cannabinoid agonists WIN 55,212-2 and CP 55,940 attenuate rotational behavior induced by a dopamine D1 but not a D2 agonist in rats with unilateral lesions of the nigrostriatal pathway. Brain Res. 1995;691:106-14.

137. Romero J, Garcia L, Cebeira M, Zadrozny D, Fernandez-Ruiz JJ, Ramos JA The endogenous cannabinoid receptor ligand, anandamide, inhibits the motor behavior: role of nigrostriatal dopaminergic neurons. Life Sci. 1995;56:2033-40

138. Fernandez-Ruiz J. The endocannabinoid system as a target for the treatment of motor dysfunction. Br J Pharmacol. 2009;156:1029-40.

139. Perez-Rial S, Garcia-Gutierrez MS, Molina JA, Perez-Nievas BG, Ledent C, Leiva C, et al. Increased vulnerability to 6-hydroxydopamine lesion and reduced 
development of dyskinesias in mice lacking CB1 cannabinoid receptors. Neurobiol Aging. 2011;32:631-45.

140. Shabani M, Hosseinmardi N, Haghani M, Shaibani V, Janahmadi M. Maternal exposure to the CB1 cannabinoid agonist WIN 55212-2 produces robust changes in motor function and intrinsic electrophysiological properties of cerebellar Purkinje neurons in rat offspring. Neuroscience. 2011;172:139-52

141. French ED, Dillon K, Wu X. Cannabinoids excite dopamine neurons in the ventral tegmentum and substantia nigra. Neuroreport. 1997;8:649-52.

142. Melis M, Gessa GL, Diana M. Different mechanisms for dopaminergic excitation induced by opiates and cannabinoids in the rat midbrain. Prog Neuropsychopharmacol Biol Psychiatry. 2000;24:993-1006.

143. Morera-Herreras T, Ruiz-Ortega JA, Gomez-Urquijo S, Ugedo L. Involvement of subthalamic nucleus in the stimulatory effect of Delta(9)-tetrahydrocannabinol on dopaminergic neurons. Neuroscience. 2008;151:817-23.

144. Lane DA, Chan J, Lupica CR, Pickel VM. Cannabinoid-1 receptor gene deletion has a compartment-specific affect on the dendritic and axonal availability of mu-opioid receptors and on dopamine axons in the mouse nucleus accumbens. Synapse. 2010;64:886-97.

145. Tanda G, Pontieri FE, Di Chiara G. Cannabinoid and heroin activation of mesolimbic dopamine transmission by a common mu1 opioid receptor mechanism. Science. 1997;276:2048-50.

146. Solinas M, Justinova Z, Goldberg SR, Tanda G. Anandamide administration alone and after inhibition of fatty acid amide hydrolase (FAAH) increases dopamine levels in the nucleus accumbens shell in rats. J Neurochem. 2006;98:408-19.

147. Pisani V, Moschella V, Bari M, Fezza F, Galati S, Bernardi G, et al. Dynamic changes of anandamide in the cerebrospinal fluid of Parkinson's disease patients. Mov Disord. 2010;25:920-4.

148. Venderova K, Ruzicka E, Vorisek V, Visnovsky P. Survey on cannabis use in Parkinson's disease: subjective improvement of motor symptoms. Mov Disord. 2004;19:1102-6.

149. Sieradzan KA, Fox SH, Hill M, Dick JP, Crossman AR, Brotchie JM. Cannabinoids reduce levodopa-induced dyskinesia in Parkinson's disease: a pilot study. Neurology. 2001;57:2108-11.

150. Carroll CB, Bain PG, Teare L, Liu X, Joint C, Wroath C, et al. Cannabis for dyskinesia in Parkinson disease: a randomized double-blind crossover study. Neurology. 2004;63:1245-50.

151. Mesnage V, Houeto JL, Bonnet AM, Clavier I, Arnulf I, Cattelin F, et al. Neurokinin B, neurotensin, and cannabinoid receptor antagonists and Parkinson disease. Clin Neuropharmacol. 2004;27:108-10.

152. DeLong MR, Wichmann T. Circuits and circuit disorders of the basal ganglia. Arch Neurol. 2007;64:20-4.

153. Surmeier DJ, Ding J, Day M, Wang Z, Shen W. D1 and D2 dopaminereceptor modulation of striatal glutamatergic signaling in striatal medium spiny neurons. Trends Neurosci. 2007;30:228-35.

154. Grillner S, Hellgren J, Menard A, Saitoh K, Wikstrom MA. Mechanisms for selection of basic motor programs-roles for the striatum and pallidum. Trends Neurosci. 2005;28:364-70.

155. Bezard E, Brotchie JM, Gross CE. Pathophysiology of levodopa-induced dyskinesia: potential for new therapies. Nat Rev Neurosci. 2001;2:577-88.

156. Hasbi A, Fan T, Alijaniaram M, Nguyen T, Perreault ML, O'Dowd BF, et al. Calcium signaling cascade links dopamine D1-D2 receptor heteromer to striatal BDNF production and neuronal growth. Proc Natl Acad Sci U S A. 2009;106:21377-82.

157. Perreault ML, Hasbi A, O'Dowd BF, George SR. Heteromeric dopamine receptor signaling complexes: emerging neurobiology and disease relevance. Neuropsychopharmacology. 2014;39:156-68.

158. Calabresi P, Picconi B, Tozzi A, Di Filippo M. Dopamine-mediated regulation of corticostriatal synaptic plasticity. Trends Neurosci. 2007;30:211-9.

159. Russo SJ, Mazei-Robison MS, Ables JL, Nestler EJ. Neurotrophic factors and structural plasticity in addiction. Neuropharmacology. 2009;56 Suppl 1:73-82.

160. Brotchie JM. CB1 cannabinoid receptor signalling in Parkinson's disease. Curr Opin Pharmacol. 2003;3:54-61.

161. van der Stelt M, Di Marzo V. The endocannabinoid system in the basal ganglia and in the mesolimbic reward system: implications for neurological and psychiatric disorders. Eur J Pharmacol. 2003;480:133-50.

162. Aceves JJ, Rueda-Orozco PE, Hernandez-Martinez R, Galarraga E, Bargas J. Bidirectional plasticity in striatonigral synapses: a switch to balance direct and indirect basal ganglia pathways. Learn Mem. 2011;18:764-73.

163. Benarroch $E$. Endocannabinoids in basal ganglia circuits: implications for Parkinson disease. Neurology. 2007;69:306-9.
164. Huot P, Brotchie JM. 5-HT(1A) receptor stimulation and L-DOPA-induced dyskinesia in Parkinson's disease: bridging the gap between serotonergic and glutamatergic mechanisms. Exp Neurol. 2011;231:195-8.

165. Adermark L, Talani G, Lovinger DM. Endocannabinoid-dependent plasticity at GABAergic and glutamatergic synapses in the striatum is regulated by synaptic activity. Eur J Neurosci. 2009;29:32-41.

166. Mathur BN, Lovinger DM. Endocannabinoid-dopamine interactions in striatal synaptic plasticity. Front Pharmacol. 2012;3:66.

167. Wilson Rl, Nicoll RA. Endocannabinoid signaling in the brain. Science. 2002;296:678-82

168. Meschler JP, Howlett AC. Signal transduction interactions between CB cannabinoid and dopamine receptors in the rat and monkey striatum. Neuropharmacology. 2001;40:918-26.

169. Glass M, Dragunow M, Faull RL. Cannabinoid receptors in the human brain: a detailed anatomical and quantitative autoradiographic study in the fetal, neonatal and adult human brain. Neuroscience. 1997;77:299-318.

170. Marcellino D, Carriba P, Filip M, Borgkvist A, Frankowska M, Bellido I, et al. Antagonistic cannabinoid CB1/dopamine D2 receptor interactions in striatal CB1/D2 heteromers. A combined neurochemical and behavioral analysis. Neuropharmacology. 2008;54:815-23.

171. Jarrahian A, Watts VJ, Barker EL. D2 dopamine receptors modulate Galphasubunit coupling of the CB1 cannabinoid receptor. J Pharmacol Exp Ther. 2004;308:880-6.

172. Pickel VM, Chan J, Kearn CS, Mackie K. Targeting dopamine D2 and cannabinoid-1 (CB1) receptors in rat nucleus accumbens. J Comp Neurol. 2006:495:299-313.

173. Kearn CS, Blake-Palmer K, Daniel E, Mackie K, Glass M. Concurrent stimulation of cannabinoid CB1 and dopamine D2 receptors enhances heterodimer formation: a mechanism for receptor cross-talk? Mol Pharmacol. 2005;67:1697-704.

174. Kreitzer AC, Malenka RC. Endocannabinoid-mediated rescue of striatal LTD and motor deficits in Parkinson's disease models. Nature. 2007:445:643-7.

175. Callen L, Moreno E, Barroso-Chinea P, Moreno-Delgado D, Cortes A, Mallol J, et al. Cannabinoid receptors CB1 and CB2 form functional heteromers in brain. J Biol Chem. 2012;287:20851-65

176. Freestone PS, Guatteo E, Piscitelli F, di Marzo V, Lipski J, Mercuri NB. Glutamate spillover drives endocannabinoid production and inhibits GABAergic transmission in the Substantia Nigra pars compacta. Neuropharmacology. 2014;79:467-75.

177. Marinelli S, Di Marzo V, Florenzano F, Fezza F, Viscomi MT, van der Stelt M, et al. $\mathrm{N}$-arachidonoyl-dopamine tunes synaptic transmission onto dopaminergic neurons by activating both cannabinoid and vanilloid receptors. Neuropsychopharmacology. 2007;32:298-308.

178. Bari M, Bonifacino T, Milanese M, Spagnuolo P, Zappettini S, Battista N, et al. The endocannabinoid system in rat gliosomes and its role in the modulation of glutamate release. Cell Mol Life Sci. 2011;68:833-45.

179. Grueter BA, Brasnjo G, Malenka RC. Postsynaptic TRPV1 triggers cell type-specific long-term depression in the nucleus accumbens. Nat Neurosci. 2010;13:1519-25

180. Morgante F, Espay AJ, Gunraj C, Lang AE, Chen R. Motor cortex plasticity in Parkinson's disease and levodopa-induced dyskinesias. Brain. 2006;129:1059-69.

181. Picconi B, Centonze D, Hakansson K, Bernardi G, Greengard P, Fisone G, et al. Loss of bidirectional striatal synaptic plasticity in L-DOPA-induced dyskinesia. Nat Neurosci. 2003;6:501-6.

182. Gerdeman GL, Ronesi J, Lovinger DM. Postsynaptic endocannabinoid release is critical to long-term depression in the striatum. Nat Neurosci. 2002;5:446-51.

183. Kreitzer AC, Malenka RC. Dopamine modulation of state-dependent endocannabinoid release and long-term depression in the striatum. J Neurosci. 2005;25:10537-45.

184. Ronesi J, Gerdeman GL, Lovinger DM. Disruption of endocannabinoid release and striatal long-term depression by postsynaptic blockade of endocannabinoid membrane transport. J Neurosci. 2004;24:1673-9.

185. Nazzaro C, Greco B, Cerovic M, Baxter P, Rubino T, Trusel M, et al. SK channel modulation rescues striatal plasticity and control over habit in cannabinoid tolerance. Nat Neurosci. 2012;15:284-93.

186. Pisani V, Madeo G, Tassone A, Sciamanna G, Maccarrone M, Stanzione P, et al. Homeostatic changes of the endocannabinoid system in Parkinson's disease. Mov Disord. 2011;26:216-22.

187. Di Filippo M, Picconi B, Tozzi A, Ghiglieri V, Rossi A, Calabresi P. The endocannabinoid system in Parkinson's disease. Curr Pharm Des. 2008;14:2337-47. 
188. Fusco FR, Martorana A, Giampa C, De March Z, Farini D, D'Angelo V, et al. Immunolocalization of $\mathrm{CB} 1$ receptor in rat striatal neurons: a confocal microscopy study. Synapse. 2004;53:159-67.

189. Picconi B, Bagetta V, Ghiglieri V, Paille V, Di Filippo M, Pendolino V, et al. Inhibition of phosphodiesterases rescues striatal long-term depression and reduces levodopa-induced dyskinesia. Brain. 2011:134:375-87.

190. Calabresi P, Gubellini P, Centonze D, Sancesario G, Morello M, Giorgi M, et al. A critical role of the nitric oxide/cGMP pathway in corticostriatal long-term depression. J Neurosci. 1999;19:2489-99.

191. Consroe P. Brain cannabinoid systems as targets for the therapy of neurological disorders. Neurobiol Dis. 1998;5:534-51.

192. Muller-Vahl KR, Kolbe H, Schneider U, Emrich HM. Cannabis in movement disorders. Forsch Komplementarmed. 1999;6 Suppl 3:23-7.

193. Papa SM. The cannabinoid system in Parkinson's disease: multiple targets to motor effects. Exp Neurol. 2008;211:334-8.

194. Heumann R, Moratalla R, Herrero MT, Chakrabarty K, Drucker-Colin R, Garcia-Montes JR, et al. Dyskinesia in Parkinson's disease: mechanisms and current non-pharmacological interventions. J Neurochem. 2014;130:472-89.

195. Price DA, Owens WA, Gould GG, Frazer A, Roberts JL, Daws LC, et al. CB1-independent inhibition of dopamine transporter activity by cannabinoids in mouse dorsal striatum. J Neurochem. 2007:101:389-96.

196. Gonzalez-Aparicio R, Moratalla R. Oleoylethanolamide reduces L-DOPA-induced dyskinesia via TRPV1 receptor in a mouse model of Parkinson s disease. Neurobio Dis. 2014;62:416-25

197. Maneuf YP, Crossman AR, Brotchie JM. The cannabinoid receptor agonist WIN 55,212-2 reduces D2, but not D1, dopamine receptor-mediated alleviation of akinesia in the reserpine-treated rat model of Parkinson's disease. Exp Neurol. 1997;148:265-70.

198. Huang P, Liu-Chen LY, Unterwald EM, Cowan A. Hyperlocomotion and paw tremors are two highly quantifiable signs of SR141716-precipitated withdrawal from delta9-tetrahydrocannabinol in C57BL/6 mice. Neurosc Lett. 2009:465:66-70

199. Fernandez-Espejo E, Caraballo I, de Fonseca FR, El Banoua F, Ferrer B, Flores JA, et al. Cannabinoid CB1 antagonists possess antiparkinsonian efficacy only in rats with very severe nigral lesion in experimental parkinsonism. Neurobiol Dis. 2005;18:591-601.

200. Gonzalez S, Scorticati C, Garcia-Arencibia M, de Miguel R, Ramos JA, Fernandez-Ruiz J. Effects of rimonabant, a selective cannabinoid CB1 receptor antagonist, in a rat model of Parkinson's disease. Brain Res. 2006;1073-1074:209-19.

201. Garcia-Arencibia M, Ferraro L, Tanganelli S, Fernandez-Ruiz J. Enhanced striatal glutamate release after the administration of rimonabant to 6-hydroxydopamine-lesioned rats. Neurosci Lett. 2008:438:10-3.

202. Nutt JG. Clinical pharmacology of levodopa-induced dyskinesia. Ann Neurol. 2000:47:S160-4. discussion S164-166.

203. Obeso JA, Olanow CW, Nutt JG. Levodopa motor complications in Parkinson's disease. Trends Neurosci. 2000;23:S2-7.

204. Ferrer B, Asbrock N, Kathuria S, Piomelli D, Giuffrida A. Effects of levodopa on endocannabinoid levels in rat basal ganglia: implications for the treatment of levodopa-induced dyskinesias. Eur J Neurosci. 2003;18:1607-14.

205. Fox SH, Henry B, Hill M, Crossman A, Brotchie J. Stimulation of cannabinoid receptors reduces levodopa-induced dyskinesia in the MPTP-lesioned nonhuman primate model of Parkinson's disease. Mov Disord. 2002;17:1180-7.

206. Cao X, Liang L, Hadcock JR, Iredale PA, Griffith DA, Menniti FS, et al. Blockade of cannabinoid type 1 receptors augments the antiparkinsonian action of levodopa without affecting dyskinesias in 1-methyl-4-phenyl1,2,3,6-tetrahydropyridine-treated rhesus monkeys. J Pharmacol Exp Ther 2007:323:318-26.

207. Giorgi M, D'Angelo V, Esposito Z, Nuccetelli V, Sorge R, Martorana A, et al. Lowered CAMP and CGMP signalling in the brain during levodopa-induced dyskinesias in hemiparkinsonian rats: new aspects in the pathogenetic mechanisms. Eur J Neurosci. 2008:28:941-50.

208. Rylander D, Parent M, O'Sullivan SS, Dovero S, Lees AJ, Bezard E, et al. Maladaptive plasticity of serotonin axon terminals in levodopa-induced dyskinesia. Ann Neurol. 2010;68:619-28.

209. Carta M, Carlsson T, Kirik D, Bjorklund A. Dopamine released from 5-HT terminals is the cause of L-DOPA-induced dyskinesia in parkinsonian rats. Brain. 2007;130:1819-33.

210. Lerner TN, Kreitzer AC. RGS4 is required for dopaminergic control of striatal LTD and susceptibility to parkinsonian motor deficits. Neuron. 2012;73:347-59.
211. Marinelli S, Di Marzo V, Berretta N, Matias I, Maccarrone M, Bernardi G, et al. Presynaptic facilitation of glutamatergic synapses to dopaminergic neurons of the rat substantia nigra by endogenous stimulation of vanilloid receptors. J Neurosci. 2003;23:3136-44.

212. Lourenco J, Cannich A, Carta M, Coussen F, Mulle C, Marsicano G. Synaptic activation of kainate receptors gates presynaptic $\mathrm{CB}(1)$ signaling at GABAergic synapses. Nat Neurosci. 2010;13:197-204.

213. Gubellini P, Picconi B, Bari M, Battista N, Calabresi P, Centonze D, et al. Experimental parkinsonism alters endocannabinoid degradation: implications for striatal glutamatergic transmission. J Neurosci. 2002;22:6900-7.

214. Paquette MA, Anderson AM, Lewis JR, Meshul CK, Johnson SW, Paul Berger S. MK-801 inhibits L-DOPA-induced abnormal involuntary movements only at doses that worsen parkinsonism. Neuropharmacology. 2010;58:1002-8.

215. Wolf E, Seppi K, Katzenschlager R, Hochschorner G, Ransmayr G, Schwingenschuh $P$, et al. Long-term antidyskinetic efficacy of amantadine in Parkinson's disease. Mov Disord. 2010;25:1357-63.

216. Ahmed I, Bose SK, Pavese N, Ramlackhansingh A, Turkheimer F, Hotton G, et al. Glutamate NMDA receptor dysregulation in Parkinson's disease with dyskinesias. Brain. 2011;134:979-86.

217. Pertwee RG, Wickens AP. Enhancement by chlordiazepoxide of catalepsy induced in rats by intravenous or intrapallidal injections of enantiomeric cannabinoids. Neuropharmacology. 1991;30:237-44.

218. Ferre S, Lluis C, Justinova Z, Quiroz C, Orru M, Navarro G, et al. Adenosine-cannabinoid receptor interactions. Implications for striatal function. Br J Pharmacol. 2010;160:443-53.

219. El-Banoua F, Caraballo I, Flores JA, Galan-Rodriguez B, Fernandez-Espejo E. Effects on turning of microinjections into basal ganglia of $D(1)$ and $D(2)$ dopamine receptors agonists and the cannabinoid $\mathrm{CB}(1)$ antagonist SR141716A in a rat Parkinson's model. Neurobiol Dis. 2004;16:377-85.

220. Zygmunt PM, Petersson J, Andersson DA, Chuang H, Sorgard M, Di Marzo V, et al. Vanilloid receptors on sensory nerves mediate the vasodilator action of anandamide. Nature. 1999;400:452-7.

221. Smart D, Gunthorpe MJ, Jerman JC, Nasir S, Gray J, Muir Al, et al. The endogenous lipid anandamide is a full agonist at the human vanilloid receptor (hVR1). Br J Pharmacol. 2000;129:227-30.

222. Ho KW, Ward NJ, Calkins DJ. TRPV1: a stress response protein in the central nervous system. Am J Neurodegener Dis. 2012;1:1-14.

223. Morgese MG, Cassano T, Cuomo V, Giuffrida A. Anti-dyskinetic effects of cannabinoids in a rat model of Parkinson's disease: role of $\mathrm{CB}(1)$ and TRPV1 receptors. Exp Neurol. 2007;208:110-9.

224. Caterina MJ, Schumacher MA, Tominaga M, Rosen TA, Levine JD, Julius D. The capsaicin receptor: a heat-activated ion channel in the pain pathway. Nature. 1997;389:816-24.

225. Lastres-Becker I, Molina-Holgado F, Ramos JA, Mechoulam R, Fernandez-Ruiz J. Cannabinoids provide neuroprotection against 6-hydroxydopamine toxicity in vivo and in vitro: relevance to Parkinson's disease. Neurobiol Dis. 2005;19:96-107.

226. Ross RA. Anandamide and vanilloid TRPV1 receptors. Br J Pharmacol. 2003;140:790-801.

227. Lee J, Di Marzo V, Brotchie JM. A role for vanilloid receptor 1 (TRPV1) and endocannabinnoid signalling in the regulation of spontaneous and L-DOPA induced locomotion in normal and reserpine-treated rats. Neuropharmacology. 2006:51:557-65.

228. Kim SR, Lee DY, Chung ES, Oh UT, Kim SU, Jin BK. Transient receptor potential vanilloid subtype 1 mediates cell death of mesencephalic dopaminergic neurons in vivo and in vitro. J Neurosci. 2005;25:662-71.

229. Garcia Mdel C, Adler-Graschinsky E, Celuch SM. Enhancement of the hypotensive effects of intrathecally injected endocannabinoids by the entourage compound palmitoylethanolamide. Eur J Pharmacol. 2009;610:75-80.

230. Di Marzo V, Bisogno T, De Petrocellis L. Anandamide: some like it hot. Trends Pharmacol Sci. 2001;22:346-9.

231. Patwardhan AM, Jeske NA, Price TJ, Gamper N, Akopian AN, Hargreaves KM. The cannabinoid WIN 55,212-2 inhibits transient receptor potential vanilloid 1 (TRPV1) and evokes peripheral antihyperalgesia via calcineurin. Proc Natl Acad Sci U S A. 2006;103:11393-8

232. Begg M, Pacher P, Batkai S, Osei-Hyiaman D, Offertaler L, Mo FM, et al. Evidence for novel cannabinoid receptors. Pharmacol Ther. 2005;106:133-45.

233. Guzman M. Effects on cell viability. Handb Exp Pharmacol. 2005;168:627-42. 
234. Javier Fernández-Ruiz SG, Julián R, José Antonio R. Cannabinoids in neurodegeneration and neuroprotection. In: Mechoulam R, editor. Cannabinoids as Therapeutics. Birkhäuser Basel: Springer Science \& Business Media; 2005. p. 79-109.

235. Mechoulam R, Shohami E. Endocannabinoids and traumatic brain injury. Mol Neurobiol. 2007;36:68-74.

236. Pertwee RG. Targeting the endocannabinoid system with cannabinoid receptor agonists: pharmacological strategies and therapeutic possibilities. Philos Trans R Soc Lond B Biol Sci. 2012;367:3353-63.

237. Galve-Roperh I, Aguado T, Palazuelos J, Guzman M. The endocannabinoid system and neurogenesis in health and disease. Neuroscientist. 2007;13:109-14.

238. Hillard CJ. Role of cannabinoids and endocannabinoids in cerebral ischemia. Curr Pharm Des. 2008;14:2347-61

239. Fernandez-Ruiz J, Romero J, Velasco G, Tolon RM, Ramos JA, Guzman M. Cannabinoid CB2 receptor: a new target for controlling neural cell survival? Trends Pharmacol Sci. 2007;28:39-45.

240. de Lago E, Fernandez-Ruiz J. Cannabinoids and neuroprotection in motor-related disorders. CNS Neurol Disord Drug Targets. 2007;6:377-87.

241. Garcia-Arencibia M, Garcia C, Fernandez-Ruiz J. Cannabinoids and Parkinson's disease. CNS Neurol Disord Drug Targets. 2009:8:432-9.

242. England TJ, Hind WH, Rasid NA, O'Sullivan SE. Cannabinoids in experimental stroke: a systematic review and meta-analysis. J Cereb Blood Flow Metab. 2015;35:348-58.

243. Capettini LS, Savergnini SQ, da Silva RF, Stergiopulos N, Santos RA, Mach F, et al. Update on the role of cannabinoid receptors after ischemic stroke. Mediators Inflamm. 2012;2012:824093.

244. Rangel-Lopez E, Colin-Gonzalez AL, Paz-Loyola AL, Pinzon E, Torres I, Serratos $\mathbb{N}$, et al. Cannabinoid receptor agonists reduce the short-term mitochondrial dysfunction and oxidative stress linked to excitotoxicity in the rat brain Neuroscience. 2015;285:97-106.

245. Zogopoulos P, Vasileiou I, Patsouris E, Theocharis S. The neuroprotective role of endocannabinoids against chemical-induced injury and other adverse effects. J Appl Toxicol. 2013;33:246-64.

246. Vendel $E$, de Lange EC. Functions of the CB1 and CB 2 receptors in neuroprotection at the level of the blood-brain barrier. Neuromolecular Med. 2014;16:620-42.

247. Ashton JC, Rahman RM, Nair SM, Sutherland BA, Glass M, Appleton I. Cerebral hypoxia-ischemia and middle cerebral artery occlusion induce expression of the cannabinoid CB2 receptor in the brain. Neurosci Lett. 2007:412:114-7.

248. Palazuelos J, Aguado T, Pazos MR, Julien B, Carrasco C, Resel E, et al. Microglial CB2 cannabinoid receptors are neuroprotective in Huntington's disease excitotoxicity. Brain. 2009;132:3152-64.

249. Nunez E, Benito C, Tolon RM, Hillard CJ, Griffin WS, Romero J. Glial expression of cannabinoid $\mathrm{CB}(2)$ receptors and fatty acid amide hydrolase are beta amyloid-linked events in Down's syndrome. Neuroscience. 2008;151:104-10

250. Benito C, Romero JP, Tolon RM, Clemente D, Docagne F, Hillard CJ, et al. Cannabinoid CB1 and CB2 receptors and fatty acid amide hydrolase are specific markers of plaque cell subtypes in human multiple sclerosis. J Neurosci. 2007;27:2396-402.

251. Yiangou $Y$, Facer $P$, Durrenberger $P$, Chessell IP, Naylor $A$, Bountra $C$, et al. COX-2, CB2 and P2X7-immunoreactivities are increased in activated microglial cells/macrophages of multiple sclerosis and amyotrophic lateral sclerosis spinal cord. BMC Neurol. 2006;6:12.

252. Esposito G, luvone T, Savani C, Scuderi C, De Filippis D, Papa M, et al. Opposing control of cannabinoid receptor stimulation on amyloid-betainduced reactive gliosis: in vitro and in vivo evidence. J Pharmacol Exp Ther. 2007;322:1144-52.

253. Kong W, Li H, Tuma RF, Ganea D. Selective CB2 receptor activation ameliorates EAE by reducing Th17 differentiation and immune cell accumulation in the CNS. Cell Immunol. 2014;287:1-17.

254. Zhang M, Martin BR, Adler MW, Razdan RK, Jallo Jl, Tuma RF Cannabinoid $\mathrm{CB}(2)$ receptor activation decreases cerebral infarction in a mouse focal ischemia/reperfusion model. J Cereb Blood Flow Metab. 2007;27:1387-96.

255. Martin-Moreno AM, Brera B, Spuch C, Carro E, Garcia-Garcia L, Delgado M, et al. Prolonged oral cannabinoid administration prevents neuroinflammation, lowers beta-amyloid levels and improves cognitive performance in Tg APP 2576 mice. J Neuroinflammation. 2012;9:8.
256. Kim K, Moore DH, Makriyannis A, Abood ME. AM1241, a cannabinoid CB2 receptor selective compound, delays disease progression in a mouse model of amyotrophic lateral sclerosis. Eur J Pharmacol. 2006;542:100-5.

257. Viscomi MT, Oddi S, Latini L, Pasquariello N, Florenzano F, Bernardi G, et al. Selective CB2 receptor agonism protects central neurons from remote axotomy-induced apoptosis through the PI3K/Akt pathway. J Neurosci. 2009;29:4564-70

258. Fernandez-Ruiz J, Garcia C, Sagredo O, Gomez-Ruiz M, de Lago E. The endocannabinoid system as a target for the treatment of neuronal damage. Expert Opin Ther Targets. 2010;14:387-404.

259. Kamat PK, Kalani A, Kyles P, Tyagi SC, Tyagi N. Autophagy of Mitochondria: A Promising Therapeutic Target for Neurodegenerative Disease. Cell Biochem Biophys. 2014;70:707-19.

260. Lee J, Giordano S, Zhang J. Autophagy, mitochondria and oxidative stress: cross-talk and redox signalling. Biochem J. 2012;441:523-40.

261. Hernandes MS, Cafe-Mendes CC, Britto LR. NADPH oxidase and the degeneration of dopaminergic neurons in parkinsonian mice. Oxid Med Cell Longev. 2013;2013:157857.

262. Hebert-Chatelain E, Reguero L, Puente N, Lutz B, Chaouloff F, Rossignol R, et al. Cannabinoid control of brain bioenergetics: Exploring the subcellular localization of the CB1 receptor. Molecular Metabolism. 2014;3:495-504.

263. Yamaori S, Ebisawa J, Okushima Y, Yamamoto I, Watanabe K. Potent inhibition of human cytochrome P450 3A isoforms by cannabidiol: role of phenolic hydroxyl groups in the resorcinol moiety. Life Sci. 2011;88:730-6.

264. Hampson AJ, Grimaldi M, Axelrod J, Wink D. Cannabidiol and (-)Delta9tetrahydrocannabinol are neuroprotective antioxidants. Proc Natl Acad Sci U S A. 1998:95:8268-73.

265. Comelli F, Bettoni I, Colleoni M, Giagnoni G, Costa B. Beneficial effects of a Cannabis sativa extract treatment on diabetes-induced neuropathy and oxidative stress. Phytother Res. 2009;23:1678-84.

266. Cassol-Jr OJ, Comim CM, Silva BR, Hermani FV, Constantino LS, Felisberto F, et al. Treatment with cannabidiol reverses oxidative stress parameters, cognitive impairment and mortality in rats submitted to sepsis by cecal ligation and puncture. Brain Res. 2010;1348:128-38.

267. Velez-Pardo C, Jimenez-Del-Rio M, Lores-Arnaiz S, Bustamante J. Protective effects of the synthetic cannabinoids CP55,940 and JWH-015 on rat brain mitochondria upon paraquat exposure. Neurochem Res. 2010;35:1323-32.

268. Pan H, Mukhopadhyay P, Rajesh M, Patel V, Mukhopadhyay B, Gao B, et al. Cannabidiol attenuates cisplatin-induced nephrotoxicity by decreasing oxidative/nitrosative stress, inflammation, and cell death. J Pharmacol Exp Ther. 2009:328:708-14.

269. Garcia-Arencibia M, Gonzalez S, de Lago E, Ramos JA, Mechoulam R, Fernandez-Ruiz J. Evaluation of the neuroprotective effect of cannabinoids in a rat model of Parkinson's disease: importance of antioxidant and cannabinoid receptor-independent properties. Brain Res. 2007;1134:162-70.

270. Campillo NE, Paez JA. Cannabinoid system in neurodegeneration: new perspectives in Alzheimer's disease. Mini Rev Med Chem. 2009;9:539-59.

271. Juknat A, Pietr M, Kozela E, Rimmerman N, Levy R, Gao F, et al. Microarray and pathway analysis reveal distinct mechanisms underlying cannabinoidmediated modulation of LPS-induced activation of BV-2 microglial cells. PLoS One. 2013;8:e61462.

272. Juknat A, Pietr M, Kozela E, Rimmerman N, Levy R, Coppola G, et al. Differential transcriptional profiles mediated by exposure to the cannabinoids cannabidiol and Delta9-tetrahydrocannabinol in BV-2 microglial cells. Br J Pharmacol. 2012;165:2512-28.

273. Garcia C, Palomo-Garo C, Garcia-Arencibia M, Ramos J, Pertwee R, Fernandez-Ruiz J. Symptom-relieving and neuroprotective effects of the phytocannabinoid Delta(9)-THCV in animal models of Parkinson's disease. Br J Pharmacol. 2011;163:1495-506.

274. Esposito G, Scuderi C, Savani C, Steardo Jr L, De Filippis D, Cottone P, et al. Cannabidiol in vivo blunts beta-amyloid induced neuroinflammation by suppressing IL-1beta and iNOS expression. Br J Pharmacol. 2007;151:1272-9.

275. Na SJ, DiLella AG, Lis EV, Jones K, Levine DM, Stone DJ, et al. Molecular profiling of a 6-hydroxydopamine model of Parkinson's disease. Neurochem Res. 2010;35:761-72

276. Marchalant Y, Brothers HM, Norman GJ, Karelina K, DeVries AC, Wenk GL. Cannabinoids attenuate the effects of aging upon neuroinflammation and neurogenesis. Neurobiol Dis. 2009;34:300-7.

277. Martin-Moreno AM, Reigada D, Ramirez BG, Mechoulam R, Innamorato N Cuadrado A, et al. Cannabidiol and other cannabinoids reduce microglial 
activation in vitro and in vivo: relevance to Alzheimer's disease. Mol Pharmacol. 2011;79:964-73.

278. Esposito G, De Filippis D, Maiuri MC, De Stefano D, Carnuccio R, luvone T. Cannabidiol inhibits inducible nitric oxide synthase protein expression and nitric oxide production in beta-amyloid stimulated PC12 neurons through p38 MAP kinase and NF-kappaB involvement. Neurosci Lett. 2006;399:91-5.

279. O'Sullivan SE, Kendall DA. Cannabinoid activation of peroxisome proliferator-activated receptors: potential for modulation of inflammatory disease. Immunobiology. 2010;215:611-6.

280. Esposito G, Scuderi C, Valenza M, Togna Gl, Latina V, De Filippis D, et al. Cannabidiol reduces Abeta-induced neuroinflammation and promotes hippocampal neurogenesis through PPARgamma involvement. PLoS One. 2011;6:e28668

281. Hill AJ, Williams CM, Whalley BJ, Stephens GJ. Phytocannabinoids as novel therapeutic agents in CNS disorders. Pharmacol Ther. 2012;133:79-97.

282. Ullrich O, Merker K, Timm J, Tauber S. Immune control by endocannabinoids - new mechanisms of neuroprotection? J Neuroimmunol. 2007; 184:127-35.

283. Helton TD, Otsuka T, Lee MC, Mu Y, Ehlers MD. Pruning and loss of excitatory synapses by the parkin ubiquitin ligase. Proc Natl Acad Sci U S A. 2008;105:19492-7.

284. Lang AE, Lozano AM. Parkinson's disease. First of two parts. N Engl J Med. 1998:339:1044-53.

285. Doble A. The role of excitotoxicity in neurodegenerative disease: implications for therapy. Pharmacol Ther. 1999;81:163-221.

286. Juttler E, Potrovita I, Tarabin V, Prinz S, Dong-Si T, Fink G, et al. The cannabinoid dexanabinol is an inhibitor of the nuclear factor-kappa $B$ (NF-kappa B). Neuropharmacology. 2004;47:580-92.

287. Sanchez-Blazquez P, Rodriguez-Munoz M, Vicente-Sanchez A, Garzon J. Cannabinoid receptors couple to NMDA receptors to reduce the production of $\mathrm{NO}$ and the mobilization of zinc induced by glutamate. Antioxid Redox Signal. 2013;19:1766-82.

288. Janero DR, Vadivel SK, Makriyannis A. Pharmacotherapeutic modulation of the endocannabinoid signalling system in psychiatric disorders: drugdiscovery strategies. Int Rev Psychiatry. 2009;21:122-33.

289. Naidoo V, Nikas SP, Karanian DA, Hwang J, Zhao J, Wood JT, et al. A new generation fatty acid amide hydrolase inhibitor protects against kainate-induced excitotoxicity. J Mol Neurosci. 2011;43:493-502.

290. Marsicano G, Goodenough S, Monory K, Hermann H, Eder M, Cannich A, et al. CB1 cannabinoid receptors and on-demand defense against excitotoxicity. Science. 2003;302:84-8.

291. Zhao P, Leonoudakis D, Abood ME, Beattie EC. Cannabinoid receptor activation reduces TNFalpha-induced surface localization of AMPAR-type glutamate receptors and excitotoxicity. Neuropharmacology. 2010:58:551-8.

292. Pintor A, Tebano MT, Martire A, Grieco R, Galluzzo M, Scattoni ML, et al. The cannabinoid receptor agonist WIN 55,212-2 attenuates the effects induced by quinolinic acid in the rat striatum. Neuropharmacology. 2006;51:1004-12.

293. Grundy RI, Rabuffetti M, Beltramo M. Cannabinoids and neuroprotection. Mol Neurobiol. 2001;24:29-51.

294. van der Stelt M, Veldhuis WB, van Haaften GW, Fezza F, Bisogno T, Bar PR, et al. Exogenous anandamide protects rat brain against acute neuronal injury in vivo. J Neurosci. 2001;21:8765-71.

295. Abood ME, Rizvi G, Sallapudi N, McAllister SD. Activation of the CB1 cannabinoid receptor protects cultured mouse spinal neurons against excitotoxicity. Neurosci Lett. 2001;309:197-201.

296. Shen M, Thayer SA. Cannabinoid receptor agonists protect cultured rat hippocampal neurons from excitotoxicity. Mol Pharmacol. 1998:54:459-62.

297. Nagayama T, Sinor AD, Simon RP, Chen J, Graham SH, Jin K, et al. Cannabinoids and neuroprotection in global and focal cerebral ischemia and in neuronal cultures. J Neurosci. 1999;19:2987-95.

298. van der Stelt M, Veldhuis WB, Maccarrone M, Bar PR, Nicolay K, Veldink GA, et al. Acute neuronal injury, excitotoxicity, and the endocannabinoid system. Mol Neurobiol. 2002;26:317-46.

299. Chiarlone A, Bellocchio L, Blazquez C, Resel E, Soria-Gomez E, Cannich A, et al. A restricted population of $C B 1$ cannabinoid receptors with neuroprotective activity. Proc Natl Acad Sci U S A. 2014;111:8257-62.

300. Stauffer B, Wallis KT, Wilson SP, Egertova M, Elphick MR, Lewis DL, et al. CRIP1a switches cannabinoid receptor agonist/antagonist-mediated protection from glutamate excitotoxicity. Neurosci Lett. 2011;503:224-8
301. Nadler V, Mechoulam R, Sokolovsky M. Blockade of 45Ca2+ influx through the $\mathrm{N}$-methyl-D-aspartate receptor ion channel by the non-psychoactive cannabinoid HU-211. Brain Res. 1993;622:79-85.

302. Nadler V, Biegon A, Beit-Yannai E, Adamchik J, Shohami E. 45Ca accumulation in rat brain after closed head injury; attenuation by the novel neuroprotective agent HU-211. Brain Res. 1995;685:1-11.

303. Eshhar N, Striem S, Kohen R, Tirosh O, Biegon A. Neuroprotective and antioxidant activities of HU-211, a novel NMDA receptor antagonist. Eur J Pharmacol. 1995;283:19-29.

304. Hampson AJ, Bornheim LM, Scanziani M, Yost CS, Gray AT, Hansen BM, et al. Dual effects of anandamide on NMDA receptor-mediated responses and neurotransmission. J Neurochem. 1998;70:671-6.

305. Sanudo-Pena MC, Patrick SL, Khen S, Patrick RL, Tsou K, Walker JM. Cannabinoid effects in basal ganglia in a rat model of Parkinson's disease. Neurosci Lett. 1998;248:171-4.

306. Blandini F, Nappi G, Tassorelli C, Martignoni E. Functional changes of the basal ganglia circuitry in Parkinson's disease. Prog Neurobiol. 2000;62:63-88

307. Frankel JP, Hughes A, Lees AJ, Stern GM. Marijuana for parkinsonian tremor. J Neurol Neurosurg Psychiatry. 1990;53:436.

308. Fagan SG, Campbell VA. The influence of cannabinoids on generic traits of neurodegeneration. Br J Pharmacol. 2014;171:1347-60.

309. More SV, Koppula S, Kim IS, Kumar H, Kim BW, Choi DK. The role of bioactive compounds on the promotion of neurite outgrowth. Molecules. 2012;17:6728-53.

310. Maccarrone M, Guzman M, Mackie K, Doherty P, Harkany T. Programming of neural cells by (endo)cannabinoids: from physiological rules to emerging therapies. Nat Rev Neurosci. 2014;15:786-801.

311. Jin K, Xie L, Kim SH, Parmentier-Batteur S, Sun Y, Mao XO, et al. Defective adult neurogenesis in CB1 cannabinoid receptor knockout mice. Mol Pharmacol. 2004:66:204-8.

312. Aguado T, Romero E, Monory K, Palazuelos J, Sendtner M, Marsicano G, et al. The CB1 cannabinoid receptor mediates excitotoxicity-induced neural progenitor proliferation and neurogenesis. J Biol Chem. 2007;282:23892-8.

313. Molina-Holgado F, Rubio-Araiz A, Garcia-Ovejero D, Williams RJ, Moore JD, Arevalo-Martin A, et al. CB2 cannabinoid receptors promote mouse neural stem cell proliferation. Eur J Neurosci. 2007;25:629-34.

314. Garcia-Ovejero D, Arevalo-Martin A, Navarro-Galve B, Pinteaux E, Molina-Holgado E, Molina-Holgado F. Neuroimmmune interactions of cannabinoids in neurogenesis: focus on interleukin-1 beta (IL-1 beta) signalling. Biochem Soc Trans. 2013;41:1577-82.

315. Skaper SD, Di Marzo V. Endocannabinoids in nervous system health and disease: the big picture in a nutshell. Philos Trans R Soc Lond B Biol Sci. 2012;367:3193-200.

316. Marxreiter F, Regensburger M, Winkler J. Adult neurogenesis in Parkinson's disease. Cell Mol Life Sci. 2013;70:459-73.

317. Le Grand JN, Gonzalez-Cano L, Pavlou MA, Schwamborn JC. Neural stem cells in Parkinson's disease: a role for neurogenesis defects in onset and progression. Cell Mol Life Sci. 2015;72:773-97.

318. Peng J, Andersen JK. Mutant alpha-synuclein and aging reduce neurogenesis in the acute 1-methyl-4-phenyl-1,2,3,6-tetrahydropyridine model of Parkinson's disease. Aging Cell. 2011:10:255-62.

319. Desplats P, Spencer B, Crews L, Pathel P, Morvinski-Friedmann D, Kosberg K, et al. alpha-Synuclein induces alterations in adult neurogenesis in Parkinson disease models via p53-mediated repression of Notch1. J Biol Chem. 2012:287:31691-702

320. Marxreiter F, Ettle B, May VE, Esmer H, Patrick C, Kragh CL, et al. Glial A3OP alpha-synuclein pathology segregates neurogenesis from anxiety-related behavior in conditional transgenic mice. Neurobiol Dis. 2013;59:38-51.

321. Khaspekov LG, Brenz Verca MS, Frumkina LE, Hermann H, Marsicano G, Lutz B. Involvement of brain-derived neurotrophic factor in cannabinoid receptor-dependent protection against excitotoxicity. Eur J Neurosci. 2004;19:1691-8

322. Scharfman H, Goodman J, Macleod A, Phani S, Antonelli C, Croll S. Increased neurogenesis and the ectopic granule cells after intrahippocampal BDNF infusion in adult rats. Exp Neurol. 2005;192:348-56.

323. Ventriglia $M$, Zanardini $R$, Bonomini $C$, Zanetti $O$, Volpe D, Pasqualetti $P$, et al. Serum brain-derived neurotrophic factor levels in different neurological diseases. Biomed Res Int. 2013;2013:901082.

324. Scalzo P, Kummer A, Bretas TL, Cardoso F, Teixeira AL. Serum levels of brain-derived neurotrophic factor correlate with motor impairment in Parkinson's disease. J Neurol. 2010;257:540-5. 
325. Maison P, Walker DJ, Walsh FS, Williams G, Doherty P. BDNF regulates neuronal sensitivity to endocannabinoids. Neurosci Lett. 2009;467:90-4.

326. Kim SH, Won SJ, Mao XO, Ledent C, Jin K, Greenberg DA. Role for neuronal nitric-oxide synthase in cannabinoid-induced neurogenesis. J Pharmacol Exp Ther. 2006;319:150-4.

327. Goncalves MB, Suetterlin P, Yip P, Molina-Holgado F, Walker DJ, Oudin MJ, et al. A diacylglycerol lipase-CB2 cannabinoid pathway regulates adult subventricular zone neurogenesis in an age-dependent manner. Mol Cell Neurosci. 2008;38:526-36.

328. Gowran A, Noonan J, Campbell VA. The multiplicity of action of cannabinoids: implications for treating neurodegeneration. CNS Neurosci Ther. 2011;17:637-44.

329. Palazuelos J, Ortega Z, Diaz-Alonso J, Guzman M, Galve-Roperh I. CB2 cannabinoid receptors promote neural progenitor cell proliferation via mTORC1 signaling. J Biol Chem. 2012;287:1198-209.

330. Compagnucci C, Di Siena S, Bustamante MB, Di Giacomo D, Di Tommaso M, Maccarrone M, et al. Type-1 (CB1) cannabinoid receptor promotes neuronal differentiation and maturation of neural stem cells. PLoS One. 2013;8:e54271.

331. Avraham HK, Jiang S, Fu Y, Rockenstein E, Makriyannis A, Zvonok A, et al. The cannabinoid $C B(2)$ receptor agonist AM1241 enhances neurogenesis in GFAP/Gp120 transgenic mice displaying deficits in neurogenesis. $\mathrm{Br}$ J Pharmacol. 2014;171:468-79.

332. Little JP, Villanueva EB, Klegeris A. Therapeutic potential of cannabinoids in the treatment of neuroinflammation associated with Parkinson's disease. Mini Rev Med Chem. 2011;11:582-90.

333. Giuffrida A, McMahon LR. In vivo pharmacology of endocannabinoids and their metabolic inhibitors: therapeutic implications in Parkinson's disease and abuse liability. Prostaglandins Other Lipid Mediat. 2010;91:90-103.

334. Koppel BS, Brust JC, Fife T, Bronstein J, Youssof S, Gronseth G, et al. Systematic review: efficacy and safety of medical marijuana in selected neurologic disorders: report of the Guideline Development Subcommittee of the American Academy of Neurology. Neurology. 2014;82:1556-63.

335. Lotan I, Treves TA, Roditi Y, Djaldetti R. Cannabis (medical marijuana) treatment for motor and non-motor symptoms of Parkinson disease: an open-label observational study. Clin Neuropharmacol. 2014;37:41-4.

336. Song L, Yang X, Ma Y, Wu N, Liu Z. The CB1 cannabinoid receptor agonist reduces $L-D O P A$-induced motor fluctuation and ERK1/2 phosphorylation in 6-OHDA-lesioned rats. Drug Des Devel Ther. 2014;8:2173-9.

337. Sayd A, Anton M, Alen F, Caso J, Pavon J, Leza J et al. Systemic Administration Of Oleoylethanolamide Protects From Neuroinflammation And Anhedonia Induced By Lps In Rats. Int J Neuropsychopharmacol. 2014. 1457-1461. Epub ahead of print.

338. Chung ES, Bok E, Chung YC, Baik HH, Jin BK. Cannabinoids prevent lipopolysaccharide-induced neurodegeneration in the rat substantia nigra in vivo through inhibition of microglial activation and NADPH oxidase. Brain Res. 2012;1451:110-6.

339. Carroll CB, Zeissler ML, Hanemann CO, Zajicek JP. Delta(9)tetrahydrocannabinol (Delta(9)-THC) exerts a direct neuroprotective effect in a human cell culture model of Parkinson's disease. Neuropathol Appl Neurobiol. 2012;38:535-47.

340. Moldzio R, Pacher T, Krewenka C, Kranner B, Novak J, Duvigneau JC, et al. Effects of cannabinoids Delta(9)-tetrahydrocannabinol, Delta(9)tetrahydrocannabinolic acid and cannabidiol in MPP+ affected murine mesencephalic cultures. Phytomedicine. 2012;19:819-24.

341. Martinez A, Macheda T, Morgese MG, Trabace L, Giuffrida A. The cannabinoid agonist WIN55212-2 decreases L-DOPA-induced PKA activation and dyskinetic behavior in 6-OHDA-treated rats. Neurosci Res. 2012;72:236-42.

342. Jeon $\mathrm{P}$, Yang $\mathrm{S}$, Jeong $H$, Kim H. Cannabinoid receptor agonist protects cultured dopaminergic neurons from the death by the proteasomal dysfunction. Anat Cell Biol. 2011;44:135-42.

343. Chung YC, Bok E, Huh SH, Park JY, Yoon SH, Kim SR, et al. Cannabinoid receptor type 1 protects nigrostriatal dopaminergic neurons against MPTP neurotoxicity by inhibiting microglial activation. J Immunol. 2011;187:6508-17

344. Walsh S, Gorman AM, Finn DP, Dowd E. The effects of cannabinoid drugs on abnormal involuntary movements in dyskinetic and non-dyskinetic 6-hydroxydopamine lesioned rats. Brain Res. 2010;1363:40-8.
345. Kelsey JE, Harris $\mathrm{O}$, Cassin J. The $\mathrm{CB}(1)$ antagonist rimonabant is adjunctively therapeutic as well as monotherapeutic in an animal model of Parkinson's disease. Behav Brain Res. 2009;203:304-7.

346. Blazquez C, Chiarlone A, Bellocchio L, Resel E, Pruunsild P, Garcia-Rincon D et al. The CB cannabinoid receptor signals striatal neuroprotection via a PI3K/Akt/mTORC1/BDNF pathway. Cell Death Differ. 2015. Epub ahead of print.

347. Sagredo O, Ramos JA, Decio A, Mechoulam R, Fernandez-Ruiz J. Cannabidiol reduced the striatal atrophy caused 3-nitropropionic acid in vivo by mechanisms independent of the activation of cannabinoid, vanilloid TRPV1 and adenosine A2A receptors. Eur J Neurosci. 2007;26:843-51.

348. Aso E, Juves S, Maldonado R, Ferrer I. CB2 cannabinoid receptor agonist ameliorates Alzheimer-like phenotype in AbetaPP/PS1 mice. J Alzheimers Dis. 2013;35:847-58.

349. Casarejos MJ, Perucho J, Gomez A, Munoz MP, Fernandez-Estevez M, Sagredo O, et al. Natural cannabinoids improve dopamine neurotransmission and tau and amyloid pathology in a mouse model of tauopathy. J Alzheimers Dis. 2013;35:525-39.

350. Wu J, Bie B, Yang H, Xu JJ, Brown DL, Naguib M. Activation of the CB2 receptor system reverses amyloid-induced memory deficiency. Neurobio Aging. 2013;34:791-804.

351. Valdeolivas S, Navarrete C, Cantarero I, Bellido ML, Munoz E, Sagredo O. Neuroprotective Properties of Cannabigerol in Huntington's Disease: Studies in R6/2 Mice and 3-Nitropropionate-lesioned Mice. Neurotherapeutics. 2015;12:185-99.

352. Scotter EL, Goodfellow CE, Graham ES, Dragunow M, Glass M. Neuroprotective potential of CB1 receptor agonists in an in vitro model of Huntington's disease. Br J Pharmacol. 2010;160:747-61.

\section{Submit your next manuscript to BioMed Central and take full advantage of:}

- Convenient online submission

- Thorough peer review

- No space constraints or color figure charges

- Immediate publication on acceptance

- Inclusion in PubMed, CAS, Scopus and Google Scholar

- Research which is freely available for redistribution 